\title{
Tissue Expression and Actin Binding of a Novel N-Terminal Utrophin Isoform
}

\author{
Richard A. Zuellig, ${ }^{1}$ Beat C. Bornhauser, ${ }^{2}$ Ralf Amstutz, ${ }^{2}$ \\ Bruno Constantin, ${ }^{3}$ and Marcus C. Schaub ${ }^{4}$ \\ ${ }^{1}$ Department of Endocrinology and Diabetes, University Hospital Zurich, 8091 Zurich, Switzerland \\ ${ }^{2}$ Department of Oncology, University Children's Hospital, University of Zurich, 8032 Zurich, Switzerland \\ ${ }^{3}$ Institut de Physiologie et Biologie Cellulaire, UMR CNRS/Université de Poitiers 6187, 86022 Poitiers Cedex, France \\ ${ }^{4}$ Institute of Pharmacology and Toxicology, University of Zurich, Winterthurerstrasse 190, 8057 Zurich, Switzerland \\ Correspondence should be addressed to Marcus C. Schaub, schaub@pharma.uzh.ch
}

Received 1 June 2011; Revised 13 July 2011; Accepted 14 July 2011

Academic Editor: J.-P. Jin

Copyright (๑) 2011 Richard A. Zuellig et al. This is an open access article distributed under the Creative Commons Attribution License, which permits unrestricted use, distribution, and reproduction in any medium, provided the original work is properly cited.

Utrophin and dystrophin present two large proteins that link the intracellular actin cytoskeleton to the extracellular matrix via the C-terminal-associated protein complex. Here we describe a novel short N-terminal isoform of utrophin and its protein product in various rat tissues ( $\mathrm{N}$-utro, $62 \mathrm{kDa}$, amino acids $1-539$, comprising the actin-binding domain plus the first two spectrin repeats). Using different $\mathrm{N}$-terminal recombinant utrophin fragments, we show that actin binding exhibits pronounced negative cooperativity (affinity constants $K_{1}=\sim 5 \times 10^{6}$ and $K_{2}=\sim 1 \times 10^{5} \mathrm{M}^{-1}$ ) and is $\mathrm{Ca}^{2+}$-insensitive. Expression of the different fragments in COS7 cells and in myotubes indicates that the actin-binding domain alone binds exlusively to actin filaments. The recombinant $\mathrm{N}$-utro analogue binds in vitro to actin and in the cells associates to the membranes. The results indicate that $\mathrm{N}$-utro may be responsible for the anchoring of the cortical actin cytoskeleton to the membranes in muscle and other tissues.

\section{Introduction}

Utrophin and dystrophin are large (395 and $427 \mathrm{kDa}$, resp.) modular proteins that link the cytoskeletal F-actin filaments to the plasmalemma. The C-terminal portion including the cysteine-rich domain associates with over a dozen of different scaffold and signaling proteins (utrophin-/dystrophin-associated protein complexes, UAPC and DAPC). These complexes are coupled via the transmembranous beta-dystroglycan to alpha-dystroglycan and to the extracellular matrix (ECM) proteins. At their N-terminus, both proteins contain a homologous actin-binding domain composed of a pair of calponin homology motifs ( $\mathrm{CH} 1$ and $\mathrm{CH} 2$ in tandem) that are connected to the long sequence of spectrin-like triple helical repeats, 22 in utrophin and 24 in dystrophin. The spectrin repeat sequences are interspersed by hinges ( $\mathrm{H} 1-$ H5) giving these structural molecules flexibility (Figure 1). Thus, these two cytoskeletal proteins directly link the intra- cellular cytoskeleton to the ECM in muscle and nonmuscle tissues.

In striated muscle, full-length dystrophin (Dp427) localises to the inner side of the plasma membrane (sarcolemma) with its N-terminus binding to nonmuscle beta- and gammaactin in the costameres which physically couple to the Z-disc of force-generating myofibres [1]. Dp427 is thought to provide mechanical stability for the muscle fibre and the necessary flexibility of its anchoring to the surrounding ECM during contraction and extension; in fact, it may act as a cellular "shock-absorber" [2, 3]. Loss of functional Dp427 causes severe muscle wasting in the fatal Duchenne's muscular dystrophy (DMD). The muscle symptoms can be improved, at least in the dystrophic mdx mouse model, by transgenic expression of Dp427 or by expression of engineered shorter versions of dystrophin comprising the essential constituents for binding to actin and the sarcolemma [4-6]. In addition, overexpression of full-length 

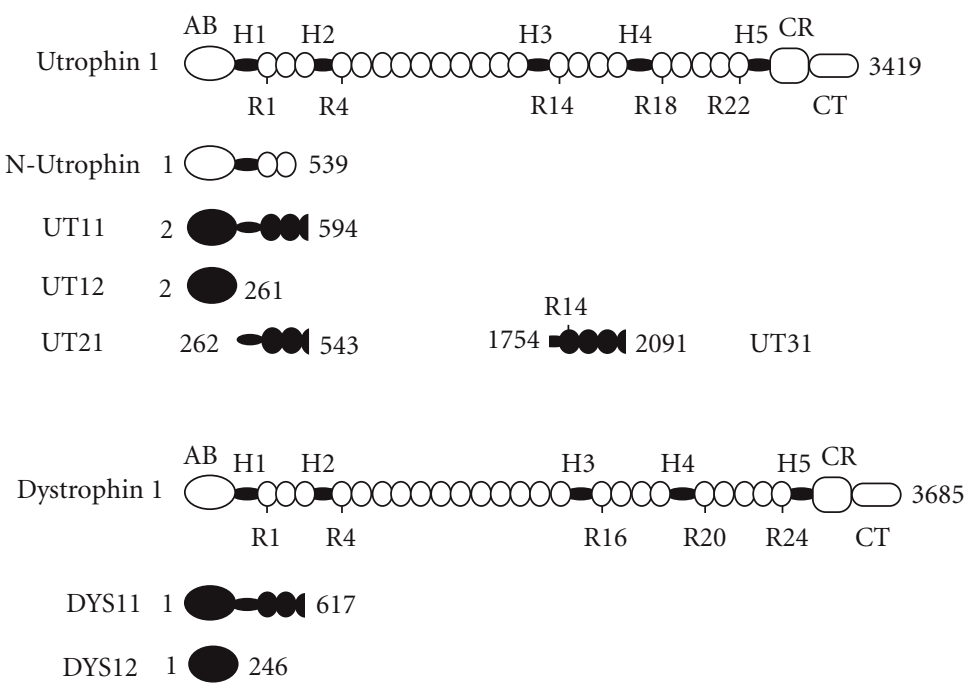

FIGURE 1: Domain structure of utrophin (rat) and dystrophin (human). Numbers denote amino acid (aa) residues according to rat utrophin. The short $\mathrm{N}$-terminal utrophin isoform (N-utro) extends from aa 1 to 539. The black sections UT11, UT12, UT21, UT31, and DYS12 were used for heterologous expression in bacteria and eukaryotic cells. The recombinant proteins were used for production of antibodies, for in vitro actin-binding studies, and for eukaryotic cell transfection. AB, actin-binding domain; H1-H5, hinge regions; R1-R24, spectrin-like triple helical repeats; CR, cystein-rich domain; CT, C-terminal domain.

utrophin (Up395) in Fiona mice lacking Dp427 localises along the sarcolemma resulting in complete recovery of normal mechanical functions and prevents the occurrence of muscular dystrophy $[7,8]$. The Fiona mouse line overexpresses Up395 under a human alpha-actin promoter in skeletal muscle, but not in the heart, over 20 times compared to control mice.

Based on the homologous domain structure (Figure 1) and the high amino acid (aa) sequence similarity, utrophin and dystrophin are expected to serve comparable functions. In fact, in fetal animals utrophin prevails and localises to the sarcolemma like dystrophin in the adult. During postnatal maturation of striated muscle, Up395 disappears from the sarcolemma and becomes restricted to the neuromuscular (NMJ) and myotendinous junctions [9]. Thus, utrophin can functionally replace dystrophin. Nevertheless, there are significant differences between the two during spaciotemporal development, in tissue and subcellular localisation, in isoform complement, and, on a molecular level, in actinbinding properties [4, 10-12]. DMD (X-linked recessive disorder) is the most common lethal disease in childhood concerning 1 in 3500 boys. In addition, about one-third of DMD patients display mental retardation related to alterations in integrated brain circuits [13]. This points to vital functions of these skeletal proteins other than muscle membrane stability.

The DMD gene localises to human chromosome Xp21 and comprises 79 exons and at least 7 internal promoters [14]. The protein Dp427 is mainly expressed in skeletal and cardiac muscle and to a lesser extent in the nervous system. It derives from three independent promoters (M: muscle; B: brain, P: cerebellar Purkinje cells) consisting of spliced unique first exons that regulate specific expression. In adult skeletal muscle, Dp427 is located at the sarcolemma and in the troughs of the postsynaptic membrane. Its N-terminal actin-binding domain contains aa 1-246 (Figure 1). Four shorter nonmuscle products harboring the cysteine-rich and $\mathrm{C}$-terminal domains, but lacking the $\mathrm{N}$-terminal actin binding domain, are expressed from downstream promoters and have been named according to their molecular weights, Dp260, Dp140, Dp116, and Dp71 [14, 15]. Dp71 has been detected in cardiac muscle and most nonmuscle tissues including brain, retina, kidney, liver, and lung $[11,12,16$, 17].

The gene of utrophin, paralogous to DMD, is located on human chromosome 6q24 containing 75 exons and 6 internal promoters $[18,19]$. Up395 is named utrophin because of its ubiquitous tissue distribution in comparison to Dp427. Expression of Up395 is driven by two independent promoters UtrnA and UtrnB [20]. The UtrnA protein is the main isoform in adult skeletal muscle and appears in the NMJ at the crests of the postsynaptic membrane folds in association with the nicotinic acetylcholine receptors (AchR). The UtrnB isoform is found enriched in vascular endothelium. Both Up395 isoforms are, however, found in brain structures and in many other tissues as well $[11,20]$. As for the DMD gene, the internal utrophin promoters give rise to several shorter $\mathrm{C}$-terminal isoforms with preservation of the cysteine-rich and the C-terminal domains, which correspond to the similar short isoforms from dystrophin and thus also lack the N-terminal actin-binding domain [14, 19, 21]. Up140 corresponds to DP140, Up113 (also called G-utrophin) to Dp116, and Up71 to Dp71.

While no short N-terminal dystrophin isoform is known, we have described the cloning of a transcript from the utrophin locus in rat C6 glioma cells which codes for a short N-terminal utrophin isoform (N-utro). N-Utro aa 1539 comprises the actin-binding domain ( $\mathrm{Ch} 1$ and $\mathrm{CH} 2$ ) plus the first two spectrin-like repeats (Figure 1) [22]. 
By immunoblotting with monoclonal antibodies (mABs) against aa 1-261 (N-terminal actin-binding domain) of utrophin, a $62 \mathrm{kDa}$ fragment was earlier detected in rat C6 glioma cells [23]. This finding suggested the existence of a truncated $\mathrm{N}$-terminal form of utrophin that was confined to the glioma cells. Indeed, its apparent molecular mass in sodium dodecyl sulfate polyacrylamide gel electrophoresis (SDSPAGE) precisely matches that of $\mathrm{N}$-utro. Here we confirm the expression of mRNA for $\mathrm{N}$-utro in all rat tissues examined including skeletal and cardiac muscle, brain, kidney, and liver. The expression of the $\mathrm{N}$-utro protein could be verified in cardiac muscle and kidney.

Recombinant utrophin fragments aa 2-594 (corresponding to N-utro), aa 2-261 (actin-binding domain), aa 262-543 (first two spectrin repeats), aa 1754-2091 (spectrin repeats R14-R16), and the dystrophin fragment aa 1-246 (actinbinding domain) were heterologously expressed in E. coli and in eukaryotic cells (Figure 1, black domains). These fragments were used for production of polyclonal antibodies (pABs) and for testing actin-binding function. Transfection of COS7 cells and myoblasts allowed to follow intracellular localisation by immunostaining. As this novel $\mathrm{N}$-terminal fragment (N-utro) is added to the panoply of the short utrophin isoform family, it is important to characterise its genetics and functional potential.

\section{Material and Methods}

2.1. Recombinant Protein Expression. Three fragments from rat utrophin (UT11, UT12, and UT31) and two from human muscular dystrophin (DYS11 and DYS12) were cloned into pQE vectors (Qiagen) for expression in Escherichia coli M15[pREP4] (Figure 1). This provides a MRGSH6 tag at the Nterminus of the proteins. In order to maintain the correct reading frame, one to two additional amino acids (aa) appeared between the tag and the in-frame proteins (see below). For DYS12, the DNA coding for aa 1-246 was cloned into the blunted BamHI site of pQE-32 after PCR amplification from a human dystrophin minigene with the following sense and antisense primers $5^{\prime}$-ATGCTTTGGTGGGAAGAAGTA- ${ }^{\prime}$ and 5' $^{\prime}$-TATTCAATGCTCACTTGTTGAGGC-3', respectively. The dystrophin minigene in pUC18 (44) was kindly provided by Dr. S. J. Winder. The other four $\mathrm{pQE}$ expression plasmids contain DNA fragments obtained by restriction digestion. For the DYS11 plasmid which codes for aa 1-617, the minigene was digested with Ncol, blunted, and digested with NarI, and the resulting NarI-NcoI-fragment was ligated into the NarI HincII-site of the DYS12 plasmid; the UT11 plasmid coding for aa 2-594 is a blunted EaeI-EaeI-fragment of clone $\alpha-213$ ligated into the blunted BamHI site of $\mathrm{pQE}-30$; for production of the UT12 plasmid coding for aa 2-261, clone $\alpha-213$ was digested with BsaHI, blunted, digested again with StuI, and the thus resulting StuI-BsaHI fragment was then ligated into the StuIHincII site of the UT11 plasmid; for the UT31 plasmid coding for aa 1754-2091, the clone $\alpha$-215 was first digested with BamHI to produce a $2.7 \mathrm{~kb}$ fragment that was subcloned into a pBluescript II SK vector (Stratagene Ltd) from which a BamHI-HincII fragment was ligated into the BamHI-HincII site of pBluescript II SK again from which a BamHI-KpnI fragment was ligated into the BamHI-KpnI site of pQE-31.

All ligation junctions were sequenced for checking the correct reading frame. Due to restriction cloning, a variable number of vector-derived aa were attached to the $\mathrm{C}$-terminus of the proteins. The following final expression constructs were obtained (numbers in brackets refer to the rat utrophin or human dystrophin primary structure):

\section{UT11: MRGSH6GS-(2-594)-RSACELGTP GRPAAKLN,}

UT12: MRGSH6GS-(2-261)-GPAAKLN,

UT31: MRGSH6T-(1754-2091)-SRGGPVPRV DLQPSLIS,

DYS11: MRGSH6GI-(1-617)-DLQPSLIS,

DYS12: MRGSH6GI-(1-246).

All five described plasmids could be expressed in Escherichia coli by induction with isopropyl- $\beta$-D-1-thiogalactopyranoside (IPTG) and purified by affinity chromatography on Ni-nitrilotriacetic acid agarose (Qiagen). UT11, UT12, and DYS12 were purified under native conditions by elution with $200 \mathrm{mM}$ imidazole (example given in Figure 2). UT31 and DYS11 could only be extracted and purified under denaturing condition in $8 \mathrm{M}$ urea with elution from the affinity column at $\mathrm{pH}$ 4.5. All protein preparations were tested by SDS-PAGE. Protein concentrations were determined by the Bradford test [24] with BSA as standard and by UV absorption at E280 with extinction coefficients of $87^{\prime} 580 \mathrm{M}^{-1} \mathrm{~cm}^{-1}$ for UT11, 39'620 for UT12, 52'040 for DYS12, and $106^{\prime} 700$ for DYS11 as derived from GCG software.

2.2. RNA Isolation. RNA was isolated from different rat tissues, brain, heart, kidney, liver, skeletal muscle, and C6 glioma cells [25] and passed twice over an oligo(dT) cellulose column (New England Biolabs) for preparation of poly $(\mathrm{A})^{+}$ RNA [26].

2.3. RT-PCR. $1 \mu \mathrm{g}$ poly $(\mathrm{A})^{+}$RNA was mixed with $1 \mu \mathrm{g}$ $\operatorname{pd}(\mathrm{N})_{6}$ or with $0.86 \mu \mathrm{g}$ oligo $(\mathrm{dT})_{12-18}$ primers, in water and incubated for $5 \mathrm{~min}$ at $70^{\circ} \mathrm{C}$. The reverse transcription was done according to manufacturer manual; in brief, the RNA-primer complex was mixed with $200 \mathrm{U}$ M-MLV reverse transcriptase (Promega, USA), $500 \mu \mathrm{M}$ dNTPs each, $50 \mathrm{mM}$ Tris-Cl pH 8.3, $75 \mathrm{mM} \mathrm{KCl,} 3 \mathrm{mM} \mathrm{MgCl}_{2}, 10 \mathrm{mM}$ DTT, $25 \mu \mathrm{L}$ reaction volume. First strand cDNA was synthesised at $37^{\circ} \mathrm{C}$ for $2 \mathrm{~h}$, stopped with $45 \mu \mathrm{L} 77 \mathrm{mM}$ EDTA/0.23 M NaOH , and heated to $95^{\circ} \mathrm{C}$ for $5 \mathrm{~min}$. After mixing with $18 \mu \mathrm{L} 1 \mathrm{M}$ Tris$\mathrm{Cl} \mathrm{pH} \mathrm{8.0,} \mathrm{the} \mathrm{first} \mathrm{strand} \mathrm{cDNA} \mathrm{was} \mathrm{extracted} \mathrm{with} \mathrm{equal}$ volumes of phenol, phenol/chloroform, and chloroform, precipitated with ethanol/ $/ \mathrm{NH}_{4} \mathrm{Ac}$ and resolved in $50 \mu \mathrm{L}$ TE.

PCR was performed in a volume of $50 \mu \mathrm{L}$ containing $1 \mathrm{U}$ Taq polymerase (HotStar, Qiagen), $200 \mu \mathrm{M}$ dNTPs each, $0.3 \mu \mathrm{M}$ primer each, $1 \times$ PCR buffer (Qiagen), $1 \mu \mathrm{L}$ first strand cDNA. Cycles were $95^{\circ} \mathrm{C} 10 \mathrm{~min}$, followed by 40 cycles $30 \mathrm{sec}$ $94^{\circ} \mathrm{C}, 30 \sec 60^{\circ} \mathrm{C}, 60 \sec 72^{\circ} \mathrm{C}$. PCR products were analysed on a $1 \%$ agarose gel (see Table 1 ). 


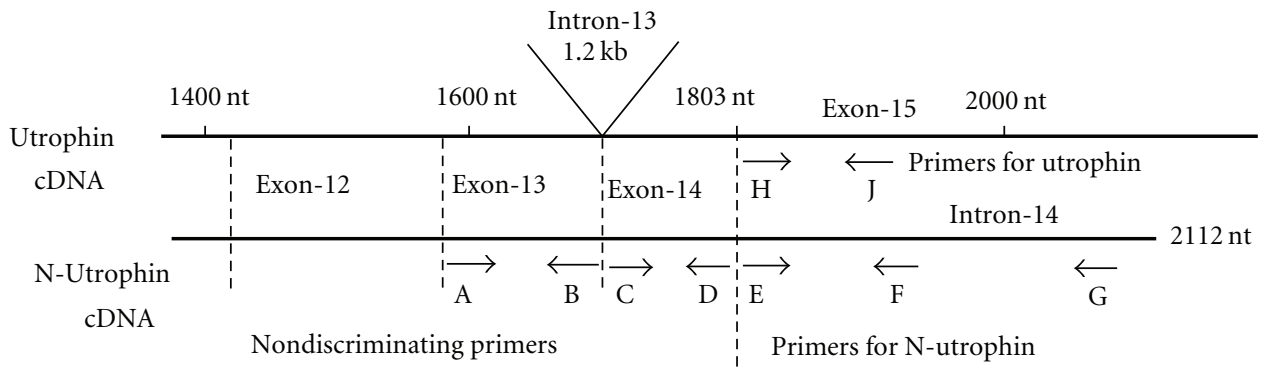

(a)

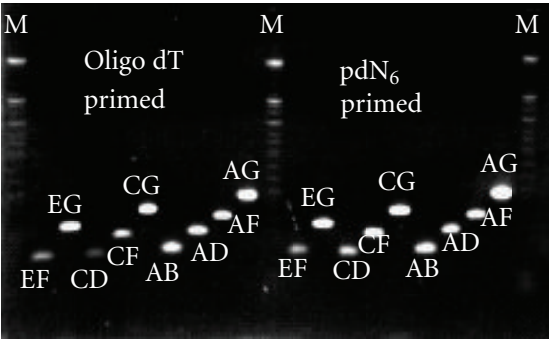

(b)

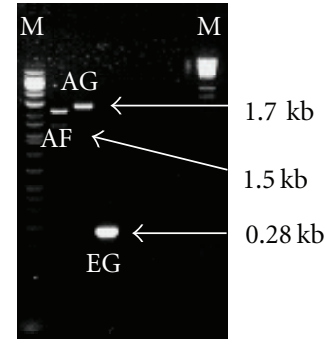

(c)

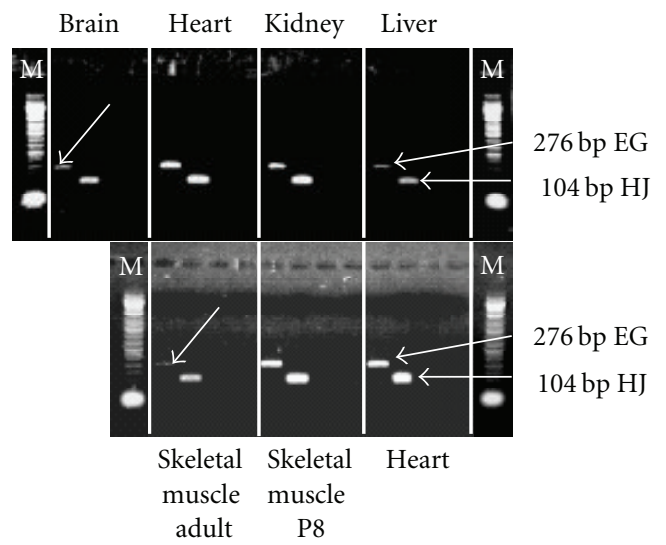

(d)

FIGURE 2: Detection of the mRNA for the N-utrophin isoform and for full-length Up395 in rat tissues by RT-PCR and electrophoresis in $1 \%$ agarose with ethidium bromide. (a) Organisation of mRNA for full-length utrophin (upper line) and for N-utrophin (lower line) with direction of primers (lettered arrows) and exon borders (dashed lines). Sequence homolgy breaks down at nucleotide (nt) 1803. Nondiscriminating primers (A, B, C, D) recognise both isoforms, while primers (E, F, G) are specific for N-utrophin, and primers (H, J) are specific for full-length utrophin. The genomic DNA contains intron-13 of 1.2 kilobases $(\mathrm{kb})$ between exon-13 and 14 . Exon numbering is in homology to that of dystrophin. (b) RT-PCR ( 40 cycles) products ranging in size from 100 to 500 base pairs (bp) from poly $(\mathrm{A})^{+} \mathrm{RNA}$ of rat kidney primed with either oligo $(\mathrm{dT})$ or $\mathrm{pd}(\mathrm{N}) 6$. (c) RT-PCR (40 cycles) products (AF and AG) from genomic rat liver DNA display sizes of 1.5 and $1.7 \mathrm{~kb}$ containing intron- 13 which adds $1.2 \mathrm{~kb}$ to each fragment. Product (EG) of $0.28 \mathrm{~kb}$ is specific for N-utrophin as control. The three black lanes between EG and the markers (M) are controls with the same primer pairs but without DNA. (d) RT-PCR (30 cycles) products (EG specific for $\mathrm{N}$-utrophin and HJ specific for full-length utrophin) in different tissues. Black lanes are negative controls without reverse transcriptase. Note the larger amount of $\mathrm{N}$-utrophin message in skeletal muscle of young rats (postnatal day 8 ) as compared to adult (arrow). Pairs of letters denote primer pairs; $\mathrm{M}$ stands for DNA markers.

2.4. Western Blots. Rat tissues from liver, brain, kidney, heart, skeletal muscle, aorta, and uterus were collected, immediately frozen in liquid nitrogen, and crushed to powder using a mortar. $100 \mu \mathrm{L}$ tissue lysis buffer per $10 \mathrm{mg}$ tissue was added (62.5 mM Tris- $\mathrm{Cl} \mathrm{pH}$ 6.8, 5\% sucrose, $5 \mathrm{mM}$ EDTA, $2 \%$ SDS and protease inhibitor (Complete Mini, Roche)), and the lysate was homogenised three times for $20 \mathrm{sec}$ with a polytron (Kinematica) and centrifuged at 20,000 $\mathrm{g}$ for $5 \mathrm{~min}$ at $4^{\circ} \mathrm{C}$. The supernatant was collected and used for analysis.
Lysates were boiled in $50 \mathrm{mM}$ Tris- $\mathrm{Cl} \mathrm{pH} 6.8,2 \%$ SDS, $5 \%$ glycerol, $10 \mathrm{mM}$ DTT and run on $4-15 \%$ gradient SDSPAGE [27]. Blotting of the gel was performed in $7 \mathrm{mM}$ Tris, $87.5 \mathrm{mM}$ glycine, $\mathrm{pH} 8.3$ (without methanol) using a Mini Trans-Blot Cell (BioRad). After staining with Ponceau-S, the membranes were cut into appropriate lanes for incubations with different antibodies and antisera (see legends of Figure 3). After incubation with the primary antibodies and a horseradish-peroxidase- (HRP-) labelled secondary antibody 
TABLE 1: Primer used for PCR (for localisation of primers along the cDNA, see Figure 2(a)).

\begin{tabular}{|c|c|}
\hline Forward primer & Backward primer \\
\hline A Rut13F & B Rut23B \\
\hline C Rut14F & D Rut24B \\
\hline \multirow{2}{*}{ E Rut18F } & F Rut25B \\
\hline & G Rut28B \\
\hline H Rut19F & J Rut41B \\
\hline \multicolumn{2}{|l|}{ PCR product size } \\
\hline \multicolumn{2}{|l|}{ A-B: $110 \mathrm{bp}$} \\
\hline \multicolumn{2}{|l|}{ A-D: 215 bp } \\
\hline \multicolumn{2}{|l|}{ A-F: 326 bp } \\
\hline \multicolumn{2}{|l|}{ A-G: 499 bp } \\
\hline \multicolumn{2}{|l|}{ C-D: 96 bp } \\
\hline \multicolumn{2}{|l|}{ C-F: 207 bp } \\
\hline \multicolumn{2}{|l|}{ C-G: 380 bp } \\
\hline \multicolumn{2}{|l|}{ E-F: 103 bp } \\
\hline \multicolumn{2}{|l|}{ E-G: 276 bp } \\
\hline \multicolumn{2}{|l|}{ H-J: 104 bp } \\
\hline \multicolumn{2}{|l|}{ Primer sequnce } \\
\hline \multicolumn{2}{|l|}{ Forward primer } \\
\hline RUT 13F & 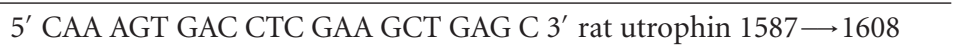 \\
\hline RUT 14F & $5^{\prime}$ GGG TGA GCG CTG GAC AGC TG 3' rat utrophin $1706 \longrightarrow 1725$ \\
\hline RUT 18F & $5^{\prime}$ GTG CAA CGA CCA TCC ATC AAG G $3^{\prime}$ rat N-utrophin $1810 \longrightarrow 1831$ \\
\hline RUT 19F & $5^{\prime}$ GTC TTT TGG AAG CTT GGC TCA CC $3^{\prime}$ rat utrophin $1804 \longrightarrow 1826$ \\
\hline \multicolumn{2}{|l|}{ Backward primer } \\
\hline RUT 23B & $5^{\prime}$ AAC TGA TCT TCC AAA ACA GCT GTG 3' rat utrophin $1673 \longleftarrow 1696$ \\
\hline RUT 24B & $\begin{array}{l}5^{\prime} \text { TGT TCT TCC AAT AAT TCC TGC CAC } 3^{\prime} \text { rat N-utrophin } \\
1778 \longleftarrow 1801\end{array}$ \\
\hline RUT 25B & $5^{\prime}$ TTC CAG AGC TCT CAC TAC AGA AG 3' rat N-utrophin $1890 \longleftarrow-1912$ \\
\hline RUT 28B & 5' CCC CAG AAT TAC GAA GGT CAC AC $3^{\prime}$ rat N-utrophin $2063 \longleftarrow 2085$ \\
\hline RUT 41B & 5' CAG ACG CCG GAC ACT GAC ACC 3' rat utrophin $1887 \longleftarrow 1907$ \\
\hline
\end{tabular}

detection was performed by SuperSignal chemiluminescence (Pierce). The different membrane lanes were precisely rejoined together and exposed to Fuji's medical X-ray film (Fuji Photo Film). Controls were done by omission of the first antibody, by using preimmune serum (not shown) and by competition with the appropriate antigen, $10 \mu \mathrm{g} / \mathrm{mL}$ (Figure 3). Molecular weight markers spanning the range from $14.4 \mathrm{kDa}$ lysozyme up to $200 \mathrm{kDa}$ myosin were used (BioRad, broad-range markers).

2.5. Antibodies and Antisera. Antibodies used were monoclonal Abs (mAb) NCL-DYS1 (Novocastra Laboratories), anti-actin monoclonal IgM (Amersham Life Science), goat anti-rabbit IgG-HRP (Pierce) and goat anti-mouse IgMHRP (Pierce). New Zealand white rabbits and guinea pigs were immunised with purified recombinant UT11 and UT31 together with Freund's adjuvant [22]. Prior to immunisation the $26 \mathrm{~N}$-terminal aa of recombinant UT11 and UT31, were sequenced for confirmation. The recombinant proteins were run on $10 \%$ SDS-PAGE and eluted for sequencing after electroblotting onto polyvinylidene difluoride membranes.
2.6. Actin-Binding Assay. Actin-binding assays were done according to Zuellig et al. [22]. Binding results are given as affinity constant $K$ which corresponds to the reciprocal value of the dissociation constant $K_{D}$. In brief, varying concentrations of the recombinant protein fragments UT11, UT12, DYS12, or BSA in actin-binding buffer $(50 \mathrm{mM}$ Trismaleate $\mathrm{pH}$ 7.4, $0.1 \mathrm{M} \mathrm{NaCl}, 1 \mathrm{mM}$ ATP, $1 \mathrm{mM}$ DTT, and either $0.5 \mathrm{mM} \mathrm{CaCl}_{2}, 2 \mathrm{mM} \mathrm{MgCl}_{2}$ or $5 \mathrm{mM}$ EGTA, $6 \mathrm{mM}$ $\mathrm{MgCl}_{2}$ were dialysed for 15 hours with one buffer change at $4^{\circ} \mathrm{C}$. Purified F-actin $(6 \mu \mathrm{M})$ [28] from rabbit fast skeletal muscle was added and the samples incubated for $30 \mathrm{~min}$ at $25^{\circ} \mathrm{C}$ in $100 \mu \mathrm{L}$ volume. Cosedimentation was carried out in a Beckman TLA-100 tabletop ultracentrifuge for $30 \mathrm{~min}$ at $100,000 \mathrm{~g}$ at $25^{\circ} \mathrm{C}$. Equal amounts of supernatant and pellet were run on $10 \%$ SDS-PAGE, stained with Coomassie Blue R250, and analysed with the Image Analysis System MCID/M2 (Imaging Research) integrating the area of the protein bands.

For the EGTA studies, the fragments (all $10 \mu \mathrm{M}$ ) were dialysed at $4^{\circ} \mathrm{C}$ for $40 \mathrm{~h}$ with three buffer changes into a buffer containing $50 \mathrm{mM}$ HEPES/NaOH pH 7.4, $0.1 \mathrm{M} \mathrm{NaCl}$, 

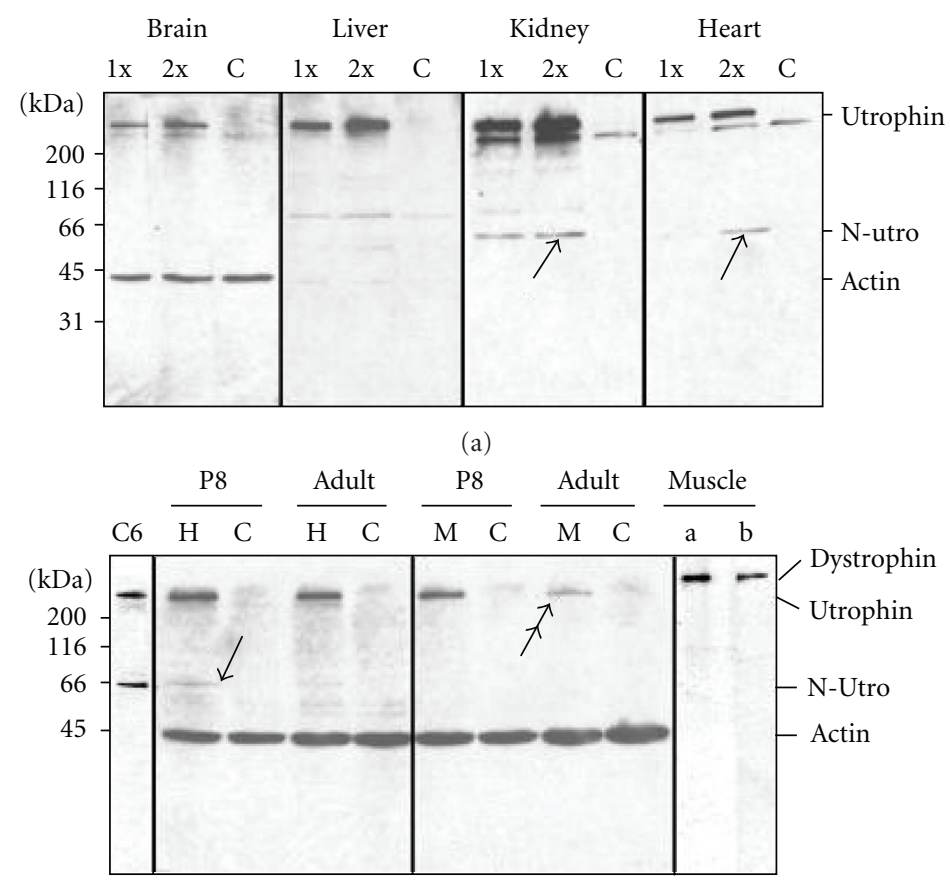

(b)

Figure 3: Immunoblots of rat tissues for full-length utrophin and N-utrophin (4-10\% SDS-PAGE). (a) Adult tissues with protein loads of $\sim 45 \mu \mathrm{g}(1 \mathrm{x}), \sim 90 \mu \mathrm{g}(2 \mathrm{x})$, and $\sim 90 \mu \mathrm{g}$ for C. All lanes stem from one gel blotted onto nitrocellulose membrane. After staining with Ponceau$\mathrm{S}$, the membrane was cut for separate immunostaining ( $1 \mathrm{x}$ and $2 \mathrm{x}$ together plus lane $\mathrm{C}$ separate). Lanes $1 \mathrm{x}$ and $2 \mathrm{x}$ were incubated with anti-UT11. Anti-UT11 recognises full-length $(\sim 395 \mathrm{kDa})$ and $\mathrm{N}$-utrophin $(\sim 65 \mathrm{kDa})$. C Lanes present competition by preincubation of the serum with recombinant UT11 antigen $(10 \mu \mathrm{L} / \mathrm{mL}$ serum) before loading onto the blot. In addition, actin $(\sim 44 \mathrm{kDa})$ was visualised in brain tissue by mixing anti-actin antibody with anit-UT11. Finally, the differently incubated membrane lanes were precisely joined together for exposure on X-ray films. Full-length utrophin is seen in all tissues and N-utrophin in kidney and heart. Competition with UT11 antigen removes full-length and $\mathrm{N}$-utrophin. The second lower band underneath the full-length utrophin may represent a degradation product which is, however, only partially removed by antigen competition. (b) The same approach was employed with the gel comprising $\mathrm{H}$, M, and $\mathrm{C}$, except that anti-actin antibody was added to all lanes for loading control and as internal molecular size marker. Protein load was $\sim 90 \mu \mathrm{g}$ protein of heart $(\mathrm{H})$ and muscle $(\mathrm{M})$ from young ( 8 days postnatal) and adult tissues. N-Utrophin can only be seen as a faint band in young heart tissue (arrow). The band of full-length utrophin is greatly reduced in adult muscle (double arrow) and abolished by competition in all samples labeled with C. For comparison, C6 rat glioma cells stained with anti-UT11 displaying full-length and N-utrophin as well as adult muscle stained with anti-DYS12 (a) and NCL-DYS1 (b) derived from different gels are included.

$1 \mathrm{mM}$ ATP, $1 \mathrm{mM} \mathrm{DTT}, 6 \mathrm{mM} \mathrm{MgCl}_{2}$, and the corresponding combination of EGTA/ $\mathrm{CaCl}_{2}$ (in $\mathrm{mM}$ ) 0/0.5, 0.5/1.0, 1.0/1.5, 5.0/6.0. Purified F-actin $(10 \mu \mathrm{M})$ was added and processed as described above.

For the calmodulin (Sigma-Aldrich) studies, the procedure was as described above except the actin and UT11 or UT12 concentrations were kept constant at $10 \mu \mathrm{M}$, and the buffer for dialysis and binding contained the following combinations of EGTA/ $\mathrm{CaCl}_{2} /$ calmodulin (all in $\mathrm{mM}$ ) $0 / 1 / 0$, $1 / 0 / 0.2,0 / 1 / 0.2,1 / 2 / 0.2$.

2.7. Circular Dichroism. Five mM dithiothreitol was added to the purified recombinant proteins before dialysis into $10 \mathrm{mM}$ Tris-Cl, pH 7.4, plus either $0.5 \mathrm{mM} \mathrm{CaCl}_{2}$ or $1 \mathrm{mM}$ EGTA plus $1.5 \mathrm{mM} \mathrm{CaCl}_{2}$ for 40 hours with three buffer changes at $4^{\circ} \mathrm{C}$. Samples were analysed by circular dichroism at $25^{\circ} \mathrm{C}$ in a Jasco J 715 spectropolarimeter with a path length of $1 \mathrm{~mm}$. Samples from two different preparations were analysed at a concentration range of $1.5-3.1 \mu \mathrm{M}$ with scanning from 260 to $190 \mathrm{~nm}$. Data was processed according to [29] and the alpha-helix content derived by infinite analysis.
2.8. Eukaryotic Expression Vectors. pBSGFP was constructed by cutting pEGFP-N1 (Clontech Laboratories, Inc.) with EcoRI and NotI, isolating the $0.7 \mathrm{~kb}$ EGFP-coding sequence, and ligating it into he EcoRI-NotI site of pBluescript II SK- (Stratagene Ltd). pBK $\Delta$ lacI was generated by cutting pBK-CMV (Stratagene Ltd) with the restriction enzymes NheI-XbaI and religating the $4.27 \mathrm{~kb}$ fragment. pEUT11Flag contains the rat utrophin sequence from aa 1 to 543 followed by the Flag peptide (DYKDDDDK); the rat utrophin sequence from clone $\alpha 213$ [22] was amplified by PCR with the primers Rut15F: 5'-TACCATGGACGGGCACCTTG-3' (NcoI, nt189->210) and Rut26B: 5'-ATGCGGCCGCTACTTATCGTCGTCATCCTTGTAATC-AGCTTCCAAAAGACACTGTTC-3' (NotI, FlagTag, nt1817->1797); the resulting product was ligated into the NcoI-NotI site of pBSGFP resulting in pBSxEUT11-Flag. This vector was cut with Bsp120I and NotI, the resulting $1.7 \mathrm{~kb}$ fragment with part of the $5^{\prime}$ UTR, the utrophin sequence, and the FlagTag was ligated into the Bsp120I and NotI site of $\mathrm{pBK} \Delta \mathrm{lacI}$ vector pEUT12 Flag contains the rat utrophin sequence 1-261 followed by the Flag peptide and was constructed the same 
way as pEUT11 Flag with the primer Rut15F and Rut27B: 5'-ATGCGGCCGCTACTTATCGTCGTCATCCTTGTAATCGTCTATAGTGACTTGCTGAGG-3' (NotI, FlagTag, nt 971>951) pEUT21 Flag contains the rat utrophin sequence 262543 followed by the Flag peptide and was constructed the same way as pEUT11-Flag with the primer Rut16F: 5'-TACCATGGCCATTCGAGAGGTGGAGACG-3' (NcoI, nt 972->992) and Rut26B.

2.9. Cell Culture. COS7 cells (ATCC-Nr: CRL 1651) were cultivated at $37^{\circ} \mathrm{C} / 5 \% \mathrm{CO}_{2}$ in Dulbecco's modified Eagle's medium (DMEM, Sigma-Aldrich) supplemented with 10\% FCS (Sera-Tech), nonessential amino acids (Sigma-Aldrich), and freshly added L-glutamine (complete DMEM).

Primary cultures of mammalian skeletal muscle cells were initiated from neonatal myogenic cells obtained by trypsinisation of muscle pieces from hind limbs of 1- to 3day-old neonatal rats. For three days following plating, cells were maintained in growth medium $\left(300 \mu \mathrm{M} \mathrm{Ca}^{2+}\right)$, consisting of HAM F12 (Invitrogen SARL, Cergy Pontoise/France) with $10 \%$ heat-inactivated horse serum (Invitrogen SARL), $10 \%$ fetal calf serum (Invitrogen SARL), and $1 \%$ antibiotics. Myoblasts underwent myogenesis in differentiation medium $\left(1.8 \mathrm{mM} \mathrm{Ca}^{2+}\right)$, containing DMEM (Invitrogen SARL) supplemented with $5 \%$ heat-inactivated horse serum. After $48 \mathrm{~h}$ of culture, this control medium (DMEM + serum) was used to promote the formation of myotubes, which occur within 15 to $18 \mathrm{~h}$. The fusion-promoting conditions were provided by the presence of a higher calcium concentration $(1,8 \mathrm{mM})$ and horse serum. This medium exchange was used as time zero for the differentiation.

2.10. Transfections. COS7 cells were seeded at $2 \times 10^{5}$ cells per dish $(4 \mathrm{~cm}$ diameter $)$ and grown over night. The next day, they were used for transfections. $3 \mu \mathrm{g}$ plasmid DNA in $75 \mu \mathrm{L}$ DMEM were mixed with $6 \mu \mathrm{L}$ Superfect Transfection Reagent (Qiagen) vortexed and incubated for $7 \mathrm{~min}$ at $37^{\circ} \mathrm{C}$. After washing the cells once with PBS, $0.5 \mathrm{~mL}$ DMEM mixed with the DNA-Superfect complex was added and the cells incubated for $3 \mathrm{~h}$ at $37^{\circ} \mathrm{C} / 5 \% \mathrm{CO}_{2}$. The cell were washed twice with PBS, and $2 \mathrm{~mL}$ complete DMEM per dish was added and the cells cultivated for $24-48 \mathrm{~h}$. After $48 \mathrm{~h}$ of culture, myotube formation was induced which occurs within 15-18 h. Two days later, the cells were used for immunocytochemistry.

Proliferating myoblasts were transfected with the plasmid cDNA by the Effectene Reagent kit (Qiagen, Courtaboeuf, France). Cells were cultured for 36 hours on glass coverslips $\left(50 \times 10^{4}\right.$ cells $)$ in proliferating medium. Cells were rinsed twice in fresh culture medium, and transfection of $1 \mu \mathrm{g}$ of plasmid cDNA per $35 \mathrm{~mm}$ plastic dish was performed in the presence of $8 \mu \mathrm{L}$ enhancer for compacting cDNA and $10 \mu \mathrm{L}$ of the effectene cationic lipid. Following a 16 hour incubation, the transfection mixture was replaced with fresh complete proliferating medium.

2.11. Immunocytochemistry. COS7 cells were washed 3 times for $2 \mathrm{~min}$ with PBS and fixed in $4 \%$ paraformaldehyde, $0.15 \mathrm{M}$ sodium phosphate buffer $\mathrm{pH} 7.4$ for $15 \mathrm{~min}$, washed
3 times 2 min with PBS, and permeabilised with $0.1 \%$ Triton-X-100 in 10\% normal goat serum (Sera-Tech) in PBS for 10 min. Primary antibodies were applied in PBS, $10 \%$ normal goat serum for $1 \mathrm{~h}$ at RT. Cells were washed 3 times 2 min with PBS, then the second antibodies were added in PBS, $10 \%$ normal goat serum for $1 \mathrm{~h}$ at RT. Cells were washed 3 times 2 min with PBS, then they were covered with glycerol gelatine (Merck) and viewed with a Carl Zeiss Axioplan2 microscope. Antibodies used were antiFLAG-M2 mouse monoclonal antibody (Stratagene Ltd.), rabbit anti-UT11, rabbit anti-UT31, goat anti-mouse IgM conjugated to Oregon green (Molecular Probes Inc.) goat anti-rabbit conjugated to Cy3 (Jackson Immunoresearch Lab.) F-actin was visualised with rhodamine-phalloidin (Molecular Probes Inc.).

Myoblasts and myotubes were fixed with $4 \%$ paraformaldehyde in TBS $(20 \mathrm{mM}$ Tris- $\mathrm{HCl}, \mathrm{pH} 7.5,150 \mathrm{mM} \mathrm{NaCl}$, $2 \mathrm{mM}$ EGTA, $2 \mathrm{mM} \mathrm{MgCl}_{2}$ ) for $20 \mathrm{~min}$ at room temperature, washed three times with TBS, and incubated with $0.5 \%$ Triton X-100/TBS for 10 min to improve permeability to the reagents. After $10 \mathrm{~min}$ of exposure to a blocking solution (TBS containing $1 \%$ bovine serum albumin; Sigma), fixed cells were incubated $1 \mathrm{~h}$ with an anti-Flag-M2 monoclonal mouse antibody $(1: 1000)$. Samples were then exposed $1 \mathrm{~h}$ in the dark to a 1:200 diluted FITC-conjugated goat antimouse antibody (Jackson Immunoresearch, West Grove, Pa, USA) altogether with TRITC-conjugated phalloidin (Sigma) for directly staining F-actin microfilaments. Samples were mounted using Vectashield mounting medium (Vector, Burlingame, Calif, USA). The immunolabelled samples were examined by confocal laser scanning microscopy (CLSM) using a BioRad MRC 1024 ES (BioRad, Hemel Hempstead, UK) equipped with an argon-krypton gas laser. The TRITC fluorochrome was excited with the $568 \mathrm{~nm}$ yellow line, and the emission of the dye was collected via a photomultiplier through a $585 \mathrm{~nm}$ long pass filter. The FITC fluorochrome was excited with the $488 \mathrm{~nm}$ blue line, and the emission of the dye was collected via a photomultiplier through a $522 \mathrm{~nm}$ band pass filter. Data were acquired using an inverted microscope (Olympus IX70, Tokyo, Japan) through a $\times 60$ oil immersion lens and processed with the Laser Sharp software, version 3.0 (BioRad). All the images were performed at equal excitation intensities ( $10 \%$ of the laser power) with a variable confocal aperture, a gain of 1500 and a black level of -3 .

2.12. Statistics. Data evaluation was done using nonlinear regression analyses with GraphPad Prism version 2 (GraphPad Software). Values are mean \pm standard error of the mean. Statistical analysis was performed using ANOVA and unpaired Student's $t$-test. Significance was accepted at $P<$ 0.05 .

\section{Results}

3.1. mRNA of N-Terminal Utrophin Isoform (N-Utro, aa 1-539) in Different Tissues. We previously described the message and protein of the short isoform N-utro in C6 rat glioma cells [22]. Here, we identify its presence in different rat tissues. 1st strand cDNA prepared from tissue 
poly $(\mathrm{A})^{+}$RNA served as template for specific probing for the occurrence of N-utro mRNA by PCR. The schematic cDNA structures for full-length utrophin (Up395) and $\mathrm{N}$-utro in the region of interest around nucleotide 1803 are given in Figure 2(a). The two sequences are identical down to nt 1802 where the deviation from Up395 begins in $\mathrm{N}$-utro with GTA, immediately followed by the stop codon TGA. The protein sequence of N-utro is thus identical to that of Up395 except for the last residue which in N-utro is Val instead of Cys in Up395. N-Utro comprises the two calponin homology domains, $\mathrm{CH} 1$ and $\mathrm{CH} 2$, followed by the first two spectrin-like repeats and ends with amino acid (aa) residue 539 (Figure 1). The GT motif at the start of the sequence diversion could represent an unused splice donor site, followed by intron material that is completely different from the sequence in Up395 [22]. This allowed the construction of forward and backward primers specific for either the N-utro or the Up395 sequence in order to identify the respective molecular species by PCR (Figure 2(a)). Putative exon-intron boundaries (dashed lines) are given in analogy to their positions in the dystrophin gene.

The 1st strand cDNA was obtained from rat kidney poly $(\mathrm{A})^{+} \mathrm{RNA}$, primed with either oligo(dT) or $\mathrm{pd}(\mathrm{N}) 6$. As oligo(dT) priming starts at the $3^{\prime}$ end and might some times stop within the sequence, we also employed $\mathrm{pd}(\mathrm{N}) 6$ random hexadeoxynucleotide for priming which starts at corresponding sites along the sequence [30]. On agarose gels, all primer pairs yielded the same distinct bands with both methods in RT-PCR (Figure 2(b)). The AB product is a 110 bp fragment encoded by exon-13, AD comprises exon13 plus exon-14, and CD only exon-14. All three fragments are shared by Up395 and N-utro. In contrast, the products $\mathrm{AF}, \mathrm{AG}, \mathrm{CF}$, and CG comprising exon-13 and/or exon-14 plus different lengths of intron-14 are specific for N-utro. EF and EG derive from the N-utro-specific intron-14. To rule out possible transcription artefacts and to confirm correctly spliced N-utro RNA, genomic rat liver DNA was directly subjected to PCR with the following primer pairs, AF, AG, and EG, (Figure $2(\mathrm{c})$ ). Both the AF and AG products comprise now the $1.2 \mathrm{~kb}$ intron-13 (see Figure 2(a)) increasing their size with a corresponding slower electrophoretic migration in the agarose gel (from $0.3 \mathrm{~kb}$ to $1.5 \mathrm{~kb}$ for $\mathrm{AF}$ and from $0.5 \mathrm{~kb}$ to 1.7 for $\mathrm{AG}$ ). The size of EG remains unchanged since it derives entirely from intron-14. Thus, splicing $\mathrm{N}$-utro from genomic DNA does not alter fragment size.

For detection of the $\mathrm{N}$-utro splice variant $\operatorname{poly}(\mathrm{A})^{+} \mathrm{RNA}$ was isolated from different tissues and $\operatorname{pd}(\mathrm{N}) 6$-primed for production of 1st strand cDNAs. These were subjected to RTPCR with primers yielding the products EG (276 bp) specific for N-utro and HJ (104 bp) specific for full-length Up395 (Figure 2(d)). Both species are seen in all tissues examined, brain, heart, kidney, liver, and skeletal muscle. The message for N-utro (EG) appeared in all tissues lower than for those Up395 (HJ). Different primer pairs do, however, not allow comparative quantification since expression efficacy may vary between different primer pairs. On the other hand, the $\mathrm{N}$-utro message (primer pair EG) was clearly fainter in adult skeletal muscle than in muscle from 8 days old rats or in adult heart. The same holds for the full-length-utrophin Up395- specific primer pair HJ. Quantitative comparison between one primer pair from the same gel under identical conditions is valid.

3.2. Utrophin and N-Utro Protein in Different Tissues. Western blots on $4-15 \%$ gradient SDS-PAGE were performed with all tissues where the mRNAs for Up395 and N-utro have been analysed (Figure 3). The polyclonal antibodies (pABs) raised against the recombinant utrophin fragments and DYS12 proved specific and did not cross-react. Probing with anti-UT11 clearly revealed Up395 in all tissues (Figures 3(a) and 3(b)) including C6 rat glioma cells which was added for comparison (Figure 3(b)). As expected, Up395 was drastically reduced in adult (double arrowhead) skeletal muscle when compared to muscle from 8 days old rats (P8). The protein bands migrating at $\sim 62 \mathrm{kDa}$ indicated by arrows in heart and kidney may represent the $\mathrm{N}$-utro protein as they coincide in position with the $\mathrm{N}$-utro band in C6 cells. Furthermore, the disappearance of the bands of Up395 and N-utro by competition with an excess of UT11 antigen (columns headed by $\mathrm{C}$ ) supports the suggestion that the band at $\sim 62 \mathrm{kDa}$ indeed represents the N-utro protein. Together with the fact that the message for the $\mathrm{N}$ utro isoform is well expressed in these tissues (kidney and heart in Figure 2(d)), the corresponding protein we observed seems to represent $\mathrm{N}$-utro. The higher molecular weight bands between Up395 and N-utro in heart and kidney are only partially outcompeted by UT11 antigen and may thus represent utrophin degradation products comprising the $\mathrm{N}$ terminal portion or nonspecific cross-reactions by the primary antiserum or the secondary antibodies. For positioning of full-length dystrophin (Dp427) in relation to Up395 adult muscle, samples were immunestained by anti-DYS12 (a, in Figure 3(b)) and by the commercial monoclonal NCL-DYS1 antibody stemming from aa 1181-1388 in the spectrin repeats 8 and 9 of the rod (b, in Figure 3(b)). The actin stained with a monoclonal IgM antibody in brain (Figure 3(a)), muscle, and heart (Figure 3(b)), was used for loading control and as intrinsic molecular weight marker.

In general, the levels of mRNAs need not necessarily correspond to the amount of protein expression. Nevertheless, it was reported that in human NCl-60 cancer cells $65 \%$ of the genes showed statistically significant transcript-protein correlation [31]. We, thus, estimated the relative content of Up395 by semiquantitative immunoblot densitometry in the various tissues from 2 to 8 days young and 6 to 8 weeks adult rats (Table 2$)$. Staining intensities $( \pm$ SEM) were all expressed in relation to that of adult liver tissue which was taken as 100. For calibration, liver and/or adult heart tissue was included in all electrophoretic runs. The results indicate that young and adult liver and brain tissue comprise similar amounts of Up395 protein, while young and adult kidney and heart as well as young skeletal muscle display significantly higher values. In adult muscle, Up395 is down to $10 \%$ of that found in young muscle as expected. The high Up395 content in adult aortic and uterine tissue is given for comparison. The content of $\mathrm{N}$-utro was generally too low for 
TABLE 2: Content of full-length utrophin in tissues from young (28 days of age) and adult (6-8 weeks old) rats. Averages of densitometric evaluation of immunoblots (SEM is given for averages from 5 experiments or more; number $n$ of experiments in brackets). Values of adult liver are set at 100. For comparison, averages of 3 experiments are given for aorta and uterus. Relative band intensities are always determined in runs together with adult liver and/or heart for calibration. For experimental details, see the Methods section.

\begin{tabular}{lcccc}
\hline Tissue & \multicolumn{2}{c}{ Young } & \multicolumn{2}{c}{ Adult } \\
\hline Liver & $(5)$ & $117 \pm 24^{*}$ & $(17)$ & 100 \\
Brain & $(5)$ & $139 \pm 22^{*}$ & $(5)$ & $105 \pm 13^{*}$ \\
Kidney & $(5)$ & $229 \pm 29$ & $(6)$ & $278 \pm 27$ \\
Heart & $(8)$ & $362 \pm 38$ & $(11)$ & $299 \pm 14$ \\
Skeletal muscle & $(12)$ & $211 \pm 18$ & $(20)$ & $21.0 \pm 1.5^{* *}$ \\
Aorta & & - & $(3)$ & 569 \\
Uterus & & - & $(3)$ & 539 \\
\hline
\end{tabular}

(*) Significantly lower $(P<0.002)$ than young and adult heart and adult kidney. $\left.{ }^{* *}\right)$ Significantly lower $(P<0.0001)$ than any other tissue with $n$ of 5 or higher.

quantitative assessment (Figure 3). The relatively high Up395 content in adult heart and kidney and in young muscle coincides with the brightest transcript bands for Up395 in the agarose gels $(\mathrm{HJ}$ product in Figure $2(\mathrm{~d})$ ) pointing to a correlation between message and protein expression. An absolute protein content for Up395 of $0.0006 \%$ of total protein was determined in adult mouse skeletal muscle [2, 32]. This is around 30 times less than dystrophin in adult muscle $(\sim 0.02 \%)$ and would allow to translate the relative values from Table 2 into approximate protein content in the different tissues.

3.3. Actin Binding of N-Terminal Fragments of Utrophin and Dystrophin. Two types of recombinant N-terminal fragments were prepared from utrophin and dystrophin for in vitro actin-binding studies (Figure 1). UT12 (coding for aa $2-261=31.6 \mathrm{kDa}$ ) and DYS12 (aa $1-246=29.9 \mathrm{kDa}$ ) comprise the actin-binding domain $(\mathrm{CH} 1$ and $\mathrm{CH} 2)$ alone. Second, UT11 (aa 2-594 = 71.1 kDa) contains in addition the first hinge region followed by two spectrin-like repeats plus 68 aa running into spectrin repeat-3. This fragment is taken as analogue to the $\mathrm{N}$-terminal utrophin isoform $(\mathrm{N}$ utro) earlier isolated from C6 rat glioma cells which comprises the two spectrin-like repeats plus 13 aa of repeat3. As mentioned above, its primary sequence is identical to that of rat utrophin except for the last residue of Cys instead of Val. All three recombinant fragments bearing a His-tag (MRGSH6GS-) at their N-terminus for affinity purification on Ni-nitrilotriacetic acid (Ni-NTA) agarose column could be eluted with $200 \mathrm{mM}$ imidazole under native conditions. The affinity purification from expression in $E$. coli is shown in SDS-PAGE (Figure 4). The electrophoretic mobility of the purified protein fragments is also revealed by immunoreaction with a $\mathrm{mAB}$ against the His-tag. Despite its calculated molecular mass of $71.1 \mathrm{kDa}$, UT11 persistently migrated at a somewhat lower position (with an apparent molecular mass of $\sim 62 \mathrm{kDa}$ ) in SDS-PAGE. The

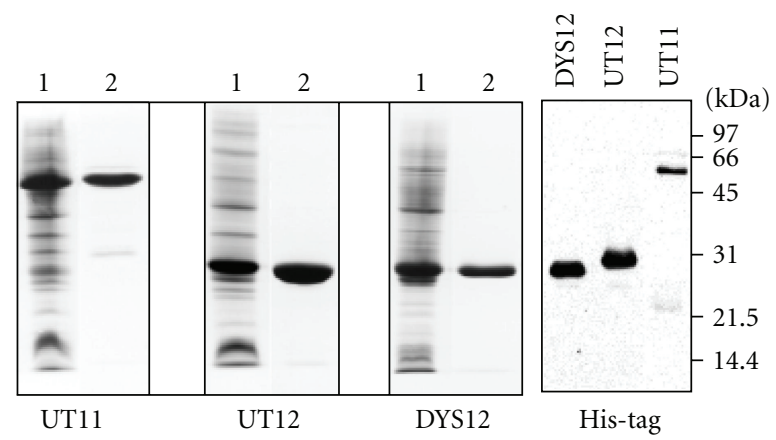

Figure 4: Expression and purification of the recombinant utrophin (UT11 and UT12) and dystrophin (DYS12) fragments used for in vitro actin-binding studies. Fragments were expressed in E. coli by induction with isopropyl- $\beta$-D-1-thiogalactopyranoside (IPTG), subsequently purified by Ni-NTA (Ni-nitrilotriacetic acid) affinity chromatography, and finally checked on $10 \%$ SDS-PAGE. Protein staining with Coomassie brilliant blue R250 of bacterial expression (lanes 1) and purified fragments (lanes 2). The fragments were also immunostained with an anti-His-tag $\mathrm{mAB}$.

DYS11 plasmid coding for aa $1-617(74.0 \mathrm{kDa})$ presents the homologue to UT11 in utrophin. Unfortunately, the protein could only be extracted and eluted from Ni-NTA agarose under denaturing conditions in $8 \mathrm{M}$ urea and $\mathrm{pH}$ 4.5. DYS11 could, therefore, not be used for actin-binding studies. Renaturation by dialysis gradually approaching "native" conditions without urea and $\mathrm{pH} 7$ was unsuccessful. Actin binding was assessed for UT11 (aa 2-594), UT12 (aa 2-261), and DYS12 (1-246) by high-speed (30 min at $1000,000 \mathrm{~g}$ and $25^{\circ} \mathrm{C}$ ) cosedimentation with fast rabbit skeletal muscle actin filaments (see Material and Methods section). SDS-PAGE was performed by loading equal volumes of supernatant and resuspended pellet. Densitometric evaluation was executed after rigorously controlled staining and destaining conditions yielding a linear relationship from 0.2 to $10 \mu \mathrm{g}$ of protein under the assumption that all proteins stained with equal intensity. Actin concentration was always kept constant and thus served as internal loading standard, while the potential ligand was varied. BSA $(\sim 67 \mathrm{kDa})$ and tropomyosin (subunit chain $\sim 33 \mathrm{kDa}$ ) were run with all series in parallel for negative and positive controls of the binding as well as control sedimentation of the ligands in the absence of actin. The electrophoretic runs of an example of UT12 binding to actin together with BSA as a control are given in Figure 5. While BSA at all concentrations occurs unbound in the supernatant (Figure 5(b)), the bound as well as the unbound portion of UT12 increase with ascending ligand concentration (Figure 5(a)). Traces of probably $\backslash$ linebreak non-polymerised actin were occasionally seen in the supernatants, never, however, exceeding $2 \%$ of total actin.

Binding data and Scatchard plots of all experiments with UT11, UT12, and DYS12 are given in Figure 6. All three protein fragments exhibit saturation binding independent of $\mathrm{Ca}^{2+}$ with UT11 and UT12, while Dys12 binding was $\mathrm{Ca}^{2+}$-sensitive (inhibition with EGTA). UT11 and UT12 both display a concave curve in the Scatchard plot indicating a 
TABle 3: Actin binding of recombinant protein fragments of utrophin and dystrophin. Parameters are derived from the binding data given in Figure 6.

\begin{tabular}{|c|c|c|c|c|c|c|c|c|}
\hline \multirow[t]{2}{*}{$\begin{array}{l}\text { Recombinant } \\
\text { protein }\end{array}$} & \multirow[t]{2}{*}{$\begin{array}{c}\text { Amino } \\
\text { acids }\end{array}$} & \multicolumn{2}{|c|}{ Affinity constants $\left(\mathrm{M}^{-1}\right)$} & \multicolumn{2}{|c|}{ Binding sites per actin monomer } & \multirow{2}{*}{$\begin{array}{c}\text { Correlation } \\
\text { coefficient } \\
(r)\end{array}$} & \multirow{2}{*}{$\begin{array}{l}\text { Total actin } \\
\text { monomers } \\
\text { per ligand at } \\
\text { high affinity }\end{array}$} & \multirow{2}{*}{$\begin{array}{c}\text { Total actin } \\
\text { monomer } \\
\text { per ligand } \\
\text { at } \\
\text { saturation }\end{array}$} \\
\hline & & $K 1$ & $K 2$ & $n 1$ & $n 2$ & & & \\
\hline UT11 & $2-594$ & $6.3 \times 10^{6}$ & $9.3 \times 10^{4}$ & 0.04 & 0.28 & 0.93 & 25 & 3.1 \\
\hline UT12 & $2-261$ & $4.6 \times 10^{6}$ & $2.5 \times 10^{5}$ & 0.14 & 0.62 & 0.98 & 7 & 1.3 \\
\hline DYS12 & $1-246$ & $1.3 \times 10^{5}$ & $3.7 \times 10^{5}$ & \multicolumn{2}{|c|}{$1.90(n 1$ plus $n 2)$} & 0.98 & - & 1.9 \\
\hline
\end{tabular}

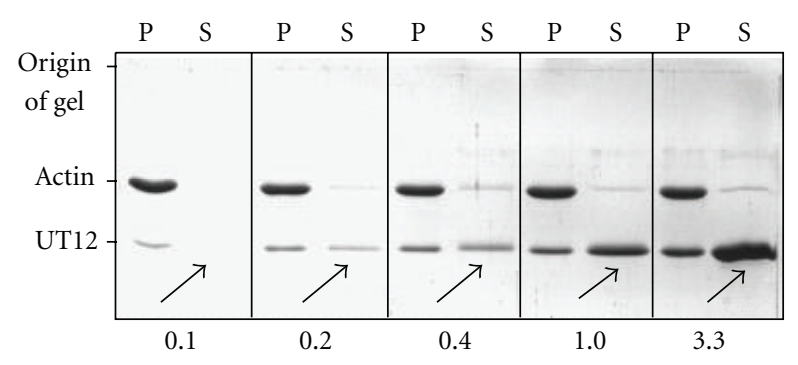

(a)

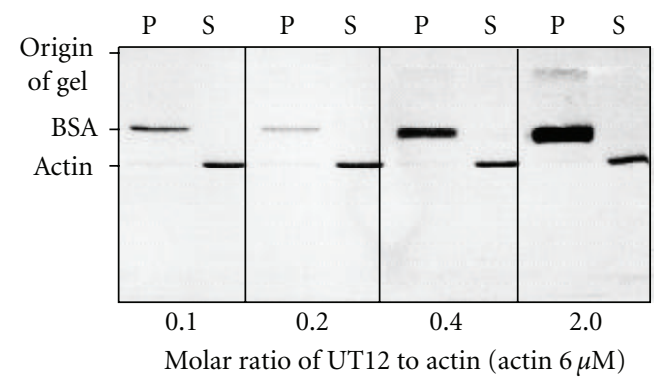

(b)

FIgURE 5: Binding assay by cosedimentation of F-actin with UT12 and BSA for control. 10\% SDS-PAGE with protein staining by Coomassie brilliant blue R250. Pellet (P) and supernatant (S) fractions with different molar ratios of UT12 (a) or BSA (b) to actin in the presence of $2 \mathrm{mM} \mathrm{MgCl}$ and $0.5 \mathrm{mM} \mathrm{CaCl}_{2}$. UT12 and BSA varied from 0.6 up to $19 \mu \mathrm{M}$. Actin was held constant at $6 \mu \mathrm{M}$. The positions of UT12, BSA, and actin are indicated at the left. Arrows point to unbound UT12 in the supernatant. At all concentrations, no BSA was bound to actin.

high affinity and a second lower affinity (Figures 6(b) and 6(d)). The binding parameters derived from Figure 6 are summarised in Table 2 . The affinity constant $K$ corresponds to the reciprocal value of the dissociation constant $K_{D}$. The higher affinity constant $K_{1}$ is for both UT fragments around $5-6 \times 10^{6} \mathrm{M}^{-1}$. The second lower $K_{2}$ is for UT11 about 70 times lower and for UT12 about 20 times lower. Concave Scatchard curves imply either the existence of two types of binding sites on filamentous actin (F-actin), or ligand-induced negative cooperativity. The two parts of the Scatchard curves for UT11 and UT12 are sufficiently distinct to allow separate evaluation. One molecule of UT11 binds with high affinity per 25 actin monomers, while UT12 binds per 7 actin monomers with high affinity (Table 3 ). This high stoichiometric relation is greatly reduced at full saturation binding involving the two affinities together. Then one molecule of UT11 binds per 3.1 actin monomers, and UT12 binds per $\sim 1.3$ actin monomers. The lower binding stoichiometry for UT12 conforms to that reported for the recombinant utrophin fragment (aa 1-261) which corresponds to UT12 [33]. Winder and coworkers [34] have reported an affinity of $\sim 5 \times 10^{4} \mathrm{M}^{-1}$ for the binding of the $\mathrm{N}$-terminal utrophin fragment (aa 1-261) to muscle F-actin with a stoichiometry of almost $1: 2$. Its affinity is, however, $\sim 100$ times lower than that reported here for $K_{1}$ and still 5 times lower than that of $K_{2}$.

In contrast to the utrophin fragments, DYS12 (aa 1246 = actin binding domain) binding to F-actin in the absence of EGTA displays a sigmoidal saturation curve with a lower slope at the beginning that increases with rising ligand concentration before saturation sets (Figure 6(e)). Such a sigmoidal binding curve is characteristic for positive cooperativity and yields a typical convex Scatchard's plot (Figure 6(f)) with a Hill coefficient of 1.52. The combined binding constant for DYS12 is $2-3 \times 10^{5} \mathrm{M}^{-1}$, and one DYS12 molecule binds per 2 actin monomers. Reported stoichiometries for recombinant N-terminal protein fragments from utrophin (aa 1-261) and dystrophin (aa 1-246) are 1:1 and $2: 1$, respectively, $[10,33]$ which agrees with our results given here. Affinities around $8 \times 10^{4} \mathrm{M}^{-1}$ have been published for several in vitro actin-binding studies with fragments from utrophin and dystrophin [33]. Our K1 values for UT11 and UT12 are definitely higher by more than an order of magnitude (Table 3). On the other hand, the binding affinity of our DYS12 with a His-tag at its N-terminus is close to $7.3 \times 10^{4} \mathrm{M}^{-1}$ reported [35] for a corresponding N-terminal dystrophin peptide (aa 1-246) with the His-tag at its Cterminus and also close to $5.3 \times 10^{4} \mathrm{M}^{-1}$ published for an untagged N-terminal peptide (aa 1-246) [36]. It may, therefore, be concluded that an attached His-tag does not grossly affect actin binding.

The apparent $\mathrm{Ca}^{2+}$ sensitivity of DYS12 binding to actin (inhibited by EGTA) concealed a peculiarity we first were not aware of. In order to evaluate the free $\mathrm{Ca}^{2+}$ ion concentration critical for the actin binding of DYS12, cosedimentation assays were performed in a $\mathrm{Ca}^{2+}$-EGTA buffer system with $5 \mathrm{mM}$ EGTA and varying amounts of $\mathrm{Ca}^{2+}$. Surprisingly, at all free $\mathrm{Ca}^{2+}$ ion concentrations up to $1 \mathrm{mM}$, the binding of 


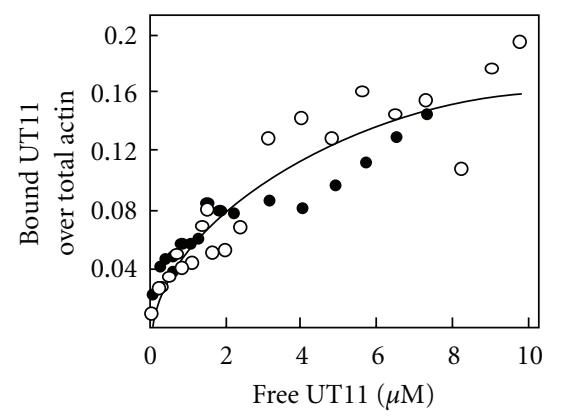

(a)

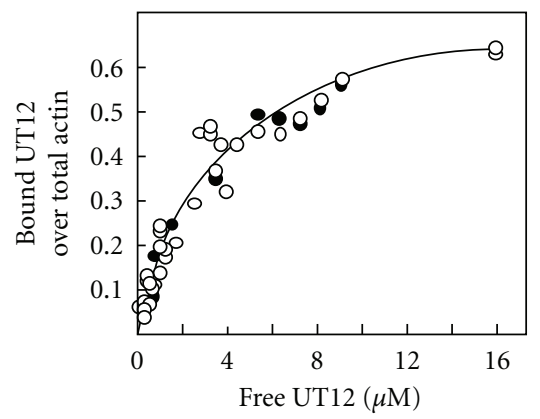

(c)

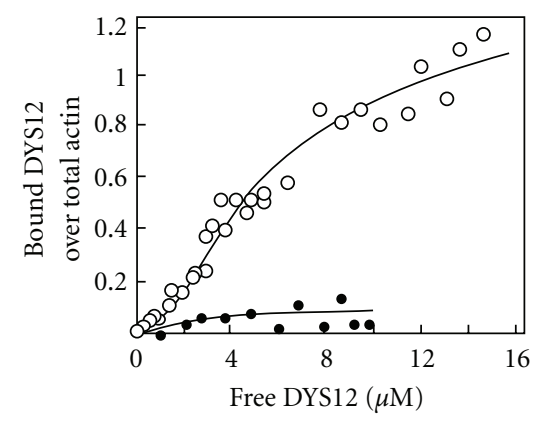

(e)

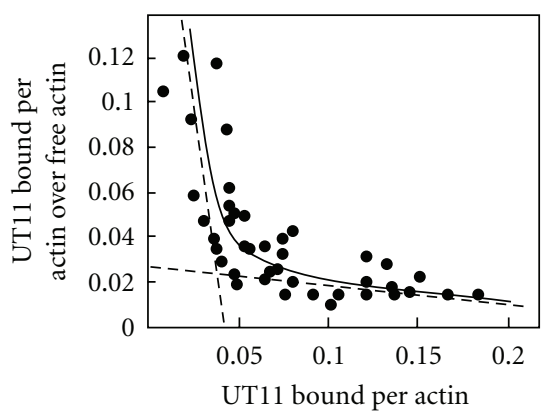

(b)

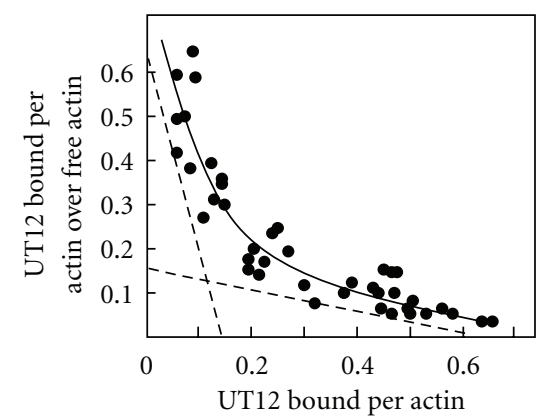

(d)

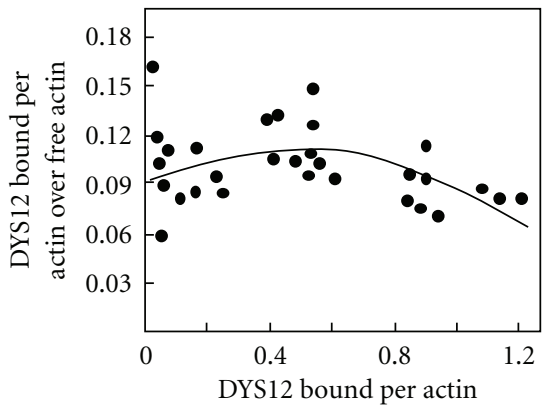

(f)

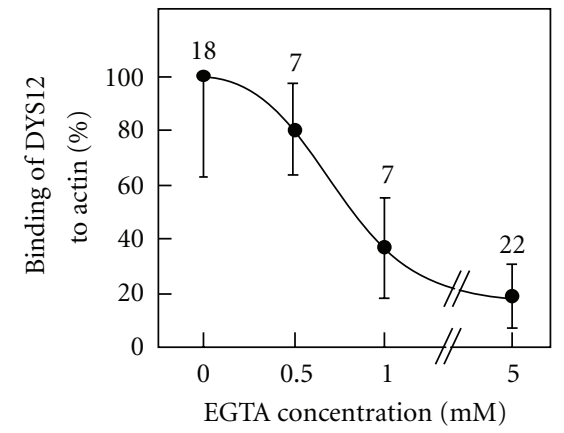

(g)

Figure 6: Binding of utrophin and dystrophin fragments to actin by cosedimentation. Assays were carried out in $2 \mathrm{mM} \mathrm{MgCl}_{2}$ and $0.5 \mathrm{mM}$ $\mathrm{CaCl}_{2}(\mathbf{O})$ or $6 \mathrm{mM} \mathrm{MgCl}$ and $5 \mathrm{mM} \mathrm{EGTA} \mathrm{( \bullet ).} \mathrm{Saturation} \mathrm{curves} \mathrm{for} \mathrm{binding} \mathrm{of} \mathrm{UT11} \mathrm{(a),} \mathrm{UT12} \mathrm{(c),} \mathrm{and} \mathrm{DYS12} \mathrm{(e)} \mathrm{at} \mathrm{the} \mathrm{left} \mathrm{side} \mathrm{with}$ the corresponding Scatchard plots at the right $(\mathrm{b}, \mathrm{d}, \mathrm{f})$. The binding curves resulted from 7 separate experiments each. All data points $(\bullet)$ are incorporated in the Scatchard plots except for DYS12 in the presence of EGTA. The concave Scatchard curves (b, d) indicate the presence of a higher and a lower affinity due to either two classes of binding sites or, alternatively, negative cooperativity. The convex curve (f) suggests positive cooperativity of DYS12 binding. Binding of DYS12 to actin was also measured with increasing concentrations of EGTA (g) in the presence of $1 \mathrm{mM} \mathrm{CaCl}_{2}$ in excess over the EGTA. Numbers at data points refer to the number of experiments. Error bars indicate SEM with $P<0.001$ for 0 and 0.5 versus 1.0 and $5.0 \mathrm{mM}$ EGTA. The small differences between 0 versus 0.5 and 1.0 versus $5.0 \mathrm{mM}$ EGTA were not significant. For further explanation, see the text.

DYS12 never exceeded 30\% of the maximal level obtained in the absence of EGTA (data not shown). Therefore, in further series of experiments, the EGTA concentration was varied with always $0.5 \mathrm{mM} \mathrm{CaCl}_{2}$ in excess over EGTA. The results in Figure 6(g) indicate that the actin binding decreases significantly at EGTA concentrations higher than $0.5 \mathrm{mM}$. No recovery of the actin binding was observed after removal of EGTA by dialysis in the presence of $0.5 \mathrm{mM} \mathrm{CaCl}_{2}$. Actin sedimentation was not affected by the presence of EGTA at any concentration used. EGTA up to $5 \mathrm{mM}$ never had an affect on actin binding either of UT11 nor UT12. For a rough estimation of possible protein structural changes, circular dichroism (CD) measurements were performed on UT12 and DYS12 in the absence of EGTA but with $0.5 \mathrm{mM}$ $\mathrm{Ca}^{2+}$ and in the presence of $1.0 \mathrm{mM}$ EGTA plus $1.5 \mathrm{mM}$ $\mathrm{Ca}^{2+}$ (spectra not shown). Both fragments exhibited a double minimum under both conditions typical for proteins with a high alpha-helical content. The results revealed a decrease of alpha helix content by $16 \%$ for UT12 and by $18 \%$ for DYS 12 in the presence of EGTA with $\mathrm{CaCl}_{2}$ in excess (Table 4). 
TABLE 4: Circular dichroism parameters of UT12 and DYS12 in the presence and the absence of EGTA each with an excess of $0.5 \mathrm{mM} \mathrm{CaCl}_{2}$ (spectrum analysis from 190 to $260 \mathrm{~nm}$, for details see the Method section).

\begin{tabular}{lcccc}
\hline & UT12 & UT12/EGTA & DYS12 & DYS12/EGTA \\
\hline Alpha helix & 60.0 & 50.9 & 62.4 & 0 \\
Beta Sheet & 0.3 & 0 & 14.0 & 0 \\
Turn & 12.7 & 19.2 & 23.6 & 23.2 \\
Random & 26.4 & 29.9 & 100 & 25.7 \\
Total & 100 & 100 & 10.238 & 100 \\
RMS* & 7.406 & 19.824 & & 16.711 \\
\hline
\end{tabular}

*RMS: root mean square for performance quality.

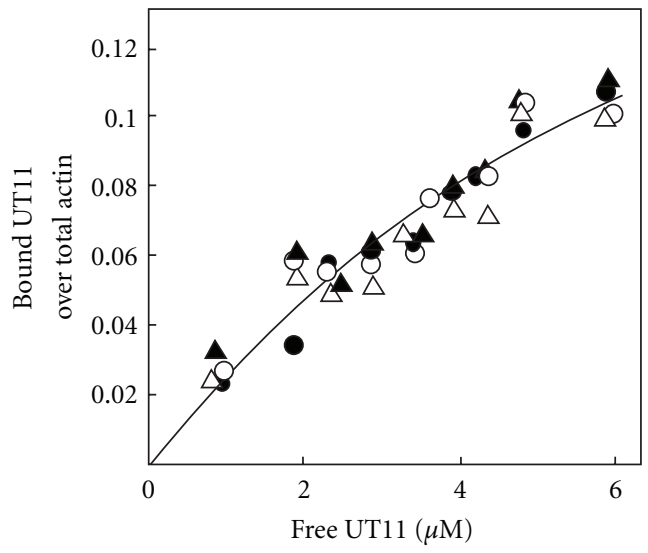

(a)

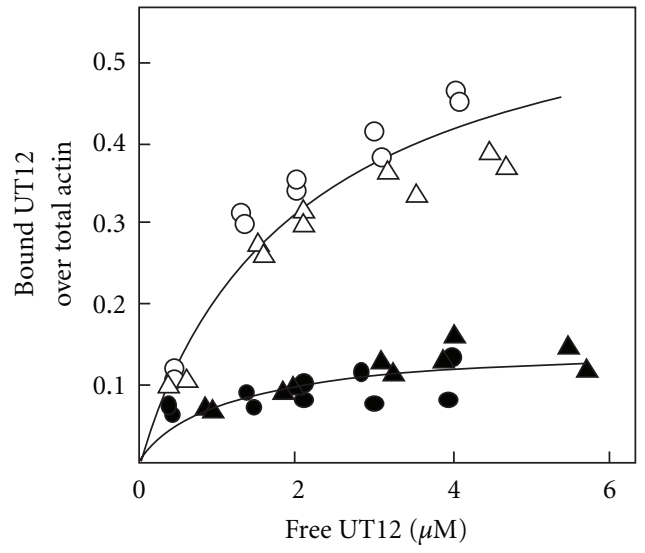

(b)

FIGURE 7: Effects of calmodulin and calcium on binding of UT11 and UT12 to actin. Calmodulin plus EGTA does not inhibit actin binding (open symbols). Calmodulin plus $\mathrm{Ca}^{2+}$ (black symbols) does not inhibit actin binding of UT11 (a), but binding of UT12 is inhibited (b). Incubation conditions: $(\mathrm{O}) \mathrm{Ca}^{2+} 1 \mathrm{mM} ;(\triangle)$ calmodulin $0.2 \mathrm{mM}$ plus EGTA $1 \mathrm{mM} ;(\bullet)$ calmodulin $0.2 \mathrm{mM}$ plus $\mathrm{Ca}^{2+} 1 \mathrm{mM} ;(\boldsymbol{\Delta})$ calmodulin $0.2 \mathrm{mM}, \mathrm{Ca}^{2+} 2 \mathrm{mM}$ plus EGTA $1 \mathrm{mM}$ (for further explanation see the text).

The reduction of alpha-helix was compensated for by an increase in turns. The decrease in alpha-helix is of similar magnitude in the two proteins and does not explain the selective impairment of EGTA on the actin-binding function of DYS12.

Winder and Kendrick-Jones [37] reported that actin binding of recombinant UTR261 (aa 1-261) was inhibited by calmodulin in the presence of $\mathrm{Ca}^{2+}$, but not in its absence. We reproduced this result with the corresponding UT12 (aa 2-261) without and with additional EGTA (Figure 7(b)). Surprisingly, calmodulin plus $\mathrm{Ca}^{2+}$ and also calmodulin, $2 \mathrm{mM} \mathrm{Ca}^{2+}$ plus $1 \mathrm{mM}$ EGTA, which both inhibited binding of UT12 did not affect actin binding of UT11 bearing two spectrin repeats (Figure 7(a)).

\subsection{Immunolocalisation of UT11, UT12, and UT21 in COS7} Cells and Myotubes. For evaluation of intracellular localisation of the actin binding domain alone (EUT12, aa 1-261), the actin-binding domain plus the first two spectrin repeats (EUT11, aa 1-543) and the two first spectrin repeats R1 and R2 alone (EUT21, aa 262-543) were inserted into eukaryotic plasmids for transfection to COS7 cells (Figure 8) as well as to myoblasts (Figure 9). For unambiguous recognition, all three recombinant fragments were fused to the "FLAG" peptide (-DYKDDDDK) at their C-terminus which can be detected by anti-Flag M2 mAB. Actin was visualised in double staining with rhodamine-phalloidin. Transfection efficiency was directly assessed by fluorescence microscopy in a number of experiments in which a GFP containing second plasmid was included. The transfected cells displayed unaltered shape and growth compared to nontransfected cells in phase contrast analysis.

COS7 cells are derived from monkey's kidney and immortalised by an origin-defective mutant of SV40 [38]. These cells are often used for transfection with recombinant plasmids, and during growth they readily adhere to glass and plastic surfaces. Spread on the substratum the cells display a fibroblast-like appearance (Figures $8(\mathrm{a}), 8(\mathrm{c})$, and $8(\mathrm{e})$ at the right). The cytoskeletal actin (probably beta- and gammaactin) appears in stress fibre structures and in densely organised cortical cytoskeleton along the cell surface membrane. In the left vertical row (a-f), anti-FLAG staining reveals the recombinant utrophin proteins. EUT12 (actin-binding domain) follows the same pattern by staining all actin structures outside the cell nucleus (Figures 8(c) and 8(d)). EUT21 (first two spectrin repeats) localises in the cell nucleus and does not associate with actin (Figures 8(e) and 8(f)). AntiUT31 (against the rod) faintly stains endogenous full-length 

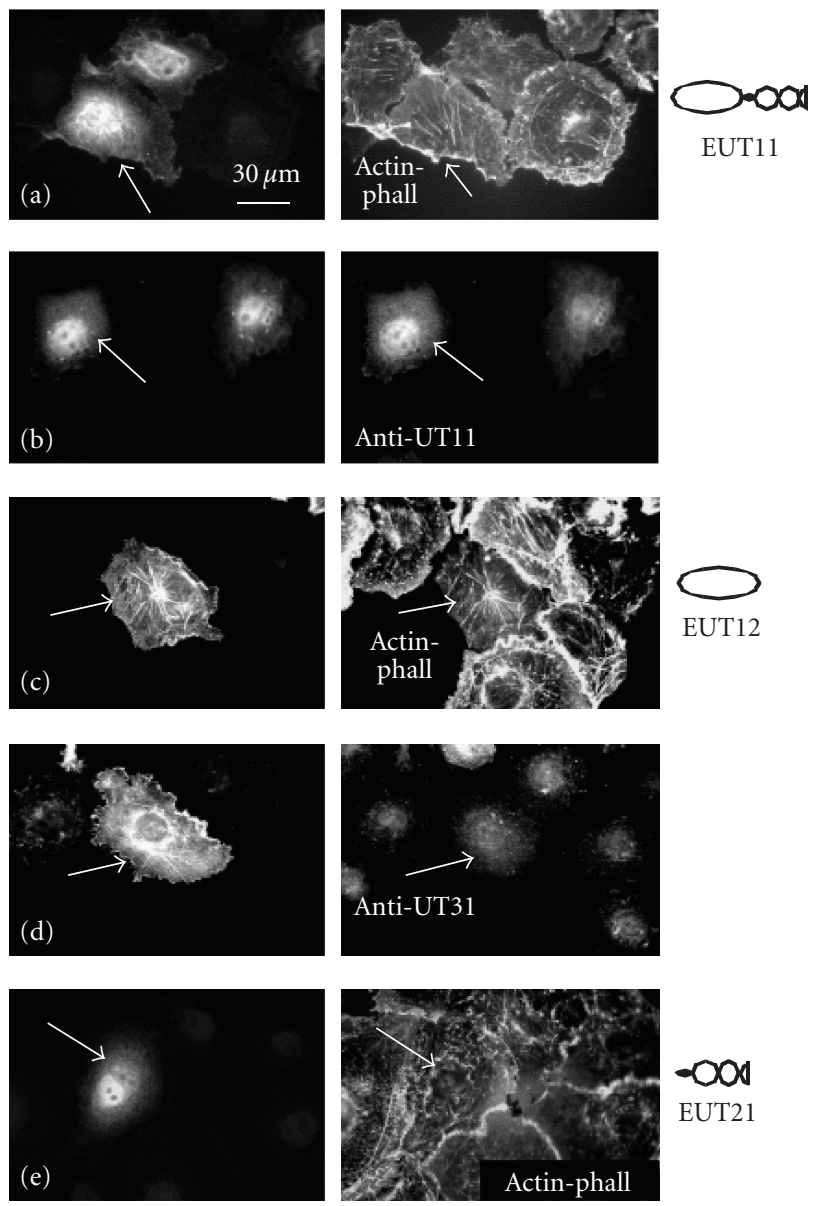

EUT21
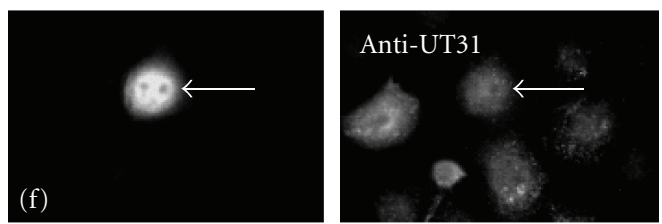

FIGURE 8: Intracellular sorting of utrophin fragments by expression of eukaryotic vectors in COS7 cells (EUT11, EUT12, and EUT21, all carrying the FLAG-tag at the C-terminus). Cells in the vertical row at the left are all stained with the anti-Flag M2 mAB ((a), (b), (c), (d), (e), (f)). Rhodamine-phalloidin staining for actin displays stress fibres and a dense cortical actin cytoskeleton along the cell membranes in the COS7 cells spreading on the substratum ((a), (c), (e) at the right). Anti-UT11 recognises full-length utrophin and N-utrophin giving intensive staining in and around the nucleus that results from the heterologously expressed EUT11 plus the endogenous utrophin ((b) at the right). Anti-UT31 (spectrin 14-16 in the rod) stains COS7 cells diffusely throughout the cytoplasm without marking any defined actin structures ((d), (f) at the right). EUT21 (first two spectrin domains) exclusively concentrates in the nuclei ((e), (f)). EUT12 (actin-binding domain alone) precisely traces the actin microfilaments and the cortical cytoskeletal structures ((c), (d)). For further explanation see the text.

utrophin (Up395) in the entire cell (d the at right). EUT11 (actin-binding plus two spectrin domains) is found in and around the cell nucleus but also throughout the cell body and faintly along the membrane (Figures $8(\mathrm{a})$ and $8(\mathrm{~b})$ ). This distribution of the FLAG-labeled EUT11 is underlined by anti-UT11 (b the at right) that intensely stains EUT11 plus the endogenous utrophin. Taken together, only the isolated actin-binding domain of utrophin (EUT12) clearly associates with stress fibres and submembranous cortical actin structures. The relatively diffuse staining of Up395 with anti-UT11 and anti-UT31 throughout the cells lets assume that additional portions of the intact molecule other than the actin and the first two spectrin domains must be involved in specific target sorting.

Transfection with the cDNA plasmids encoding the utrophin fragments EUT11, EUT12, and EUT21 fused to the FLAG Tag was performed on myoblasts from neonatal rat hindleg muscle in primary cell cultures. After $48 \mathrm{~h}$ of culture, myotube formation was induced, and two days later the fixed cells were immunostained for the utrophin fragments with FITC-conjugated $\mathrm{AB}$ and with TRITC-conjugated phalloidin for F-actin microfilaments. Staining patterns were assessed by confocal laser scanning microscopy (Figure 9). The antiFlag stained utrophin fragments are displayed in the left 

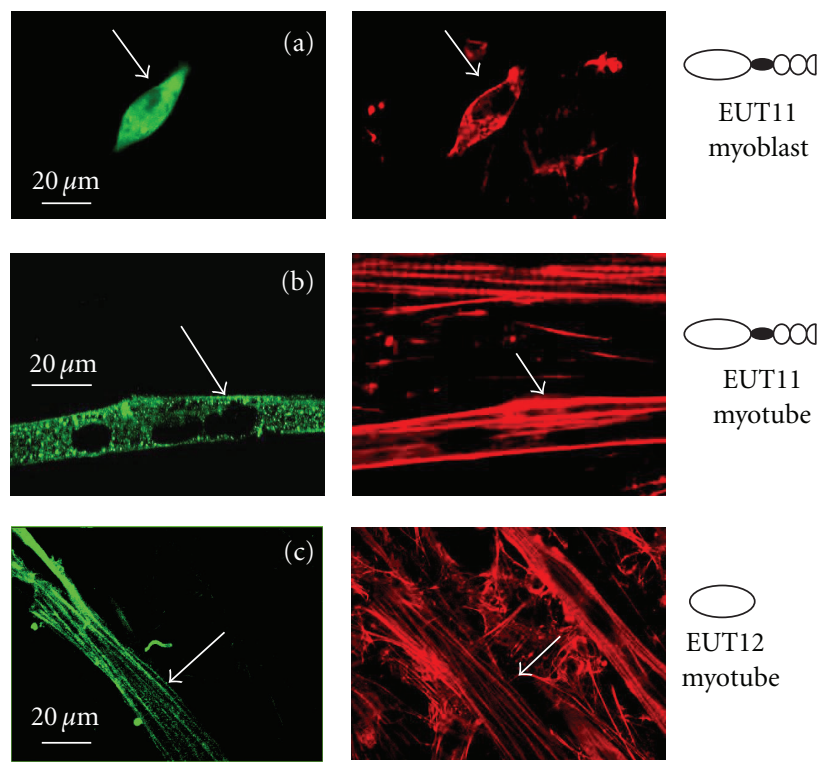

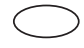 \\ EUT12 \\ myotube}
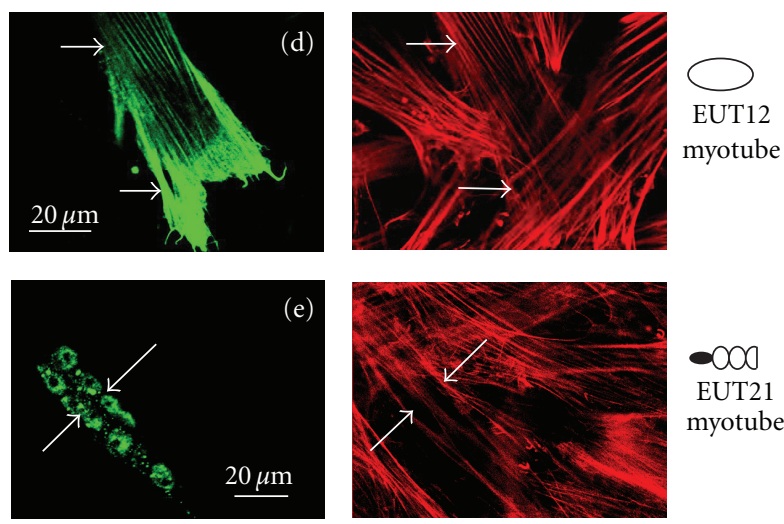

\section{- 00}

EUT21

myotube
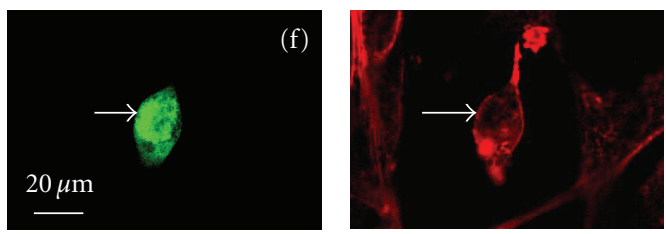

$\infty$

EUT21

myoblast

FIGURE 9: Intracellular sorting of utrophin fragments by expression of eukaryotic vectors in myoblast and myotube primary cultures (EUT11, EUT12, and EUT21, all carrying the FLAG-tag at the C-terminus). In each picture in the left vertical row ((a)-(f)), one transfected cell (green) is present stained with anti-FLAG for the corresponding utrophin fragment. Staining with rhodamine-phalloidin for actin reveals a variable number of red cells in each picture ((b)-(e) in the right vertical row) indicating that the transfected cells often fuse with nontransfected cells when forming myotubes. EUT11 and EUT21 solidly stain nucleus and cytoplasm in single spindle-shaped myoblasts. EUT12 (actinbinding domain) sharply stains actin microfilaments ((c) and (d)) superimposable to the red pattern of actin stain ((c) and (d) at the right). EUT12 also concentrates in regions where actin may attach to the substratum (d). EUT11 distributes over the cytoplasm in a diffuse and punctate manner (b) leaving the myotube nuclei unstained. In contrast, EUT21 is almost exclusively confined to the cell nuclei. For further explanations, see the Methods section and the text.

vertical row in green, while F-actin is stained in red in the right vertical row. In all cases there appears only one transfcted green cell (Figures 9(b)-9(e)). Evidently the transfected myoblasts often fuse to myotubes together with nontransfected cells. In the spindle-shaped myoblasts (Figures 9(a) and 9(f)), staining for EUT11 and EUT21 fills the entire cell including the nucleus. The myotubes (Figures 9(b)-9(e)) display a rich filamentous actin structural network, probably mostly nonmuscle beta- and gamma-isoforms of the cortical cytoskeleton. Sarcomere structures are not yet visible except for just a beginning in the nontransfected myotube in red at the top of Figure 9(b). EUT12 (actin-binding domain alone) staining precisely follows the actin structures throughout the myotubes and becomes especially dense at the ends where the cells adhere to the substratum (Figures 9(c) and 9(d)). EUT11 staining does not follow the actin filaments but remains diffuse and punctate, sparing out the nuclei. Its staining pattern suggests that EUT11 may attach to the 
myotube surface membrane. EUT21 seems almost entirely confined to a row of nuclei in Figure 9(e).

The general staining patterns of the three recombinant fragments from the $\mathrm{N}$-terminal utrophin region in myotubes and in COS7 cells are similar in kind. The isolated actinbinding domain (EUT12) clearly associates with F-actin structures in both cell types, while the other two protein fragments more variably appear in the cytoplasm, along the membranes or in the cell nuclei.

\section{Discussion}

4.1. $m R N A$ and N-Utro Protein in Rat Tissues. The occurrence of message and protein of a novel N-terminal short utrophin isoform (N-utro) in different rat tissues is reported here for the first time. In addition, its intracellular sorting as well as in vitro actin-binding properties was examined. The message for full-length utrophin (Up395) is the highest in cardiac muscle, in skeletal muscle of early postnatal animals, and in kidney. It is apparently lower in adult skeletal muscle, brain, and liver (product HJ in Figure 2(d)). Although a quantitative correlation between protein and message can often not be demonstrated, in this case the Up395 content (expressed relative to that in adult liver) was significantly higher in those tissues where the message was also higher (Table 1). This correlation between message and protein is remarkable in view of the notorious difficulties encountered with quantitative immunoblotting involving transfer of large proteins such as Up395 to nitrocellulose membranes for electrophoresis. Correspondingly, the protein $\mathrm{N}$-utro could be only visualised by immunoblots in those tissues with the highest message levels for kidney and cardiac muscle (Figure 3). In the other, tissues its content was too low for detection.

4.2. Actin Binding. Since N-utro is the only N-terminal short isoform possessing the actin-binding domain known so far, extensive binding studies were done with the recombinant analogue UT11 (aa 2-594, actin-binding domain plus two spectrin repeats) in comparison to UT12 (aa 2-261) and DYS12 (1-246), the latter two comprising the actin-binding domain alone (Figures 6 and 7 plus Table 3). Several of the findings presented here shed light on fundamental differences in actin-binding function between these $\mathrm{N}$-terminal fragments of utrophin and dystrophin.

First, the high- and low-binding affinities for UT11 and UT12 greatly affect the stoichiometric relation of ligand to actin. With the high affinity, UT11 binds to every 25 th actin and UT12 to every 7 th actin. The two additional spectrin repeats in UT11 differentiate the two utrophin fragments from one another. These two motifs of UT11 must be responsible for the more extended spacing of this ligand as compared to UT12. With saturation binding the second lower affinity reduces the spacing of the ligands along the F-actin filament to $\sim 3$ actin per UT11 and close to one actin per UT12. In our experiments, there were no additional proteins present such a tropomyosin or troponin components that could impart a defined spacing periodicity. Thus, the high affinity binding results suggest that UT11 with two spectrin repeats affects the actin filament binding properties over a distance of 25 actin monomers. But on increasing ligand saturation, additional UT11 molecules seem able to associate with actin at lower affinity in between those already bound with high affinity. The overall stoichiometry is, thus, reduced to three actin monomers per UT11. A similar deliberation applies to the shorter UT12 without spectrin repeats. With high affinity, the actin-binding domain alone affects the accessibility of 7 actins in the filament, while on saturation including low-affinity binding, the stoichiometry drops to $\sim 1: 1$. Taken together, our results suggest, under the assumption of indistinguishable binding sites of the individual actin monomers in the filament, that the distinct lower affinity is induced by the binding of the ligands UT11 and UT12 with high affinity. Furthermore, in view of the different spacing induced by UT11 or UT12 binding with high affinity, it seems most unlikely that a second class of defined binding sites with lower intrinsic affinity exists along the actin filament. Several reports on N-terminal utrophin and dystrophin fragments mention similar actin-binding affinities in the range of $\sim 10^{5} \mathrm{M}^{-1}$ and similar stoichiometries for binding saturation as given here [33-35, 39]. However, these published binding affinities may routinely represent the lower values at full saturation, while the higher values at low ligand concentrations of utrophin fragments may have been overlooked. Actin-binding studies have mostly been performed with skeletal muscle alpha-actin. Yet the cytoskeletal Up395 and Dp427 primarily interact in vivo with cytosolic beta- and gamma-actin which are ubiquitously expressed. Even in striated muscle, the cortical gamma cytoskeletal actin in the costameres between the sarcolemma and the Zdisks presents the interaction partner for Up395 and Dp427 [40]. Nevertheless, the different actin isoforms share over 93\% sequence identity and can replace each other to a large extent [40]. Reassuringly, it was reported that the binding characteristics of utrophin and dystrophin and their fragments to nonmuscle actin are almost identical to those with skeletal muscle actin [8,33-35]. The binding affinities are in some cases slightly higher for cytoplasmic than for skeletal muscle actin.

Second, in stark contrast to the negative cooperativity in the binding of the utrophin N-terminal fragments, DYS12 binds to actin filaments with moderately positive cooperativity (Hill coefficient of 1.5) and a stoichiometry at saturation of one ligand per two actin monomers. Positive cooperativity with a Hill coefficient of 3.5 was also reported for actin binding of the dystrophin fragment (aa 1-246) that corresponds to UT12 $[6,36]$. Tropomyosin was reported to affect neither affinity nor stoichiometry in the binding of dystrophin in vitro $[39,41]$. Curious enough, Up395 and Dp427 both bind to actin by lateral association along the actin filament but do not compete in their binding with one another [2]. Dp427 comprises 5 basic spectrin repeats within the stretch of R11 to $\mathrm{R} 17$ in the middle of the rod. This spectrin repeat stretch firmly associates with F-actin and reinforces the binding of the N-terminal domain to actin. The actin interaction of the spectrin repeat region is salt dependent pointing to its electrostatic nature. The two actin-binding regions in dystrophin are separated by $\sim 1200$ aa. Ervasti has presented a 
model for dystrophin as molecular shock absorber during muscle contraction. On stretch the electrostatic interaction of the positively charged spectrin repeats would slide along the negative surface of the actin filament and, thus, dampen elastic recoil [2]. This is not the case with Up395. Up395 lacks the basic nature of the corresponding spectrin repeats in the middle of the rod, and, consequently, this stretch does not interact with actin [42]. Instead, the 10 spectrin repeats immediately following the $\mathrm{N}$-terminal actin-binding domain firmly interact with actin and stabilise the binding. This interaction is not salt dependent and, thus, may be of hydrophobic nature. The N-terminal domain and the following spectrin repeats function as a single contiguous unit [43]. This is compatible with the notion that UT11 with the two first spectrin repeats occupies more actin monomers than UT12. Consequently, it may be speculated that intact Up395, because of its contiguous binding region from the Nterminus through to spectrin repeat R10, does not function as molecular shock absorber but rather as stabiliser of cortical actin filaments in costameres and in the postsynaptic membranes of NMJs [2, 4].

Finally, we assessed potential regulation by $\mathrm{Ca}^{2+}$ and calmodulin of fragment binding to actin. The actin binding of UT11 and UT12 proved to be independent of $\mathrm{Ca}^{2+}$ and not affected by EGTA. However, the interaction of DYS12 with actin is virtually abolished in the presence of more than $0.5 \mathrm{mM}$ EGTA even in the simultaneous presence of $0.5 \mathrm{mM}$ $\mathrm{CaCl}_{2}$ in excess. It was not possible to restore the binding function to DYS12 by gradually removing EGTA in dialysis. Molecular parameters derived from circular dichroism measurements indicated a reduction of alpha-helix content by around $17 \%$ for both fragments in the presence of $5 \mathrm{mM}$ EGTA plus $6 \mathrm{mM} \mathrm{CaCl}_{2}$. This does not explain the selective abolition of DYS12 actin binding by EGTA. The inhibition of actin binding of UTR261 (or UT12) by calmodulin in the presence of $\mathrm{Ca}^{2+}$ was suggested to be due to its competitive binding to the $\mathrm{CH} 1$ domain [37]. Immediately upstream of the actin-binding sequence-2 (ABS2) near the C-terminus of $\mathrm{CH} 1$ localises a highly hydrophobic stretch of 15 aa that may accommodate calmodulin complexed to $\mathrm{Ca}^{2+}$. It is speculated that this represents a mode of regulation in vivo for the interaction of the $\mathrm{N}$-terminal utrophin with actin. Our results indicate, however, that the two spectrin-like repeats in UT12 are sufficient to prevent such a calmodulin/ $\mathrm{Ca}^{2+}$ mode of regulation. In vivo with Up395 running along the actin filament firmly bound from its $\mathrm{N}$-terminal actin-binding domain through to spectrin repeat R10, it is unlikely that this part of the molecule responds to subtle Ca-calmodulin regulation. Furthermore, these findings are of particular interest in relation to the novel N-utro isoform.

4.3. Intracellular Sorting of N-Terminal Utrophin Fragments. To define their intracellular localization, COS7 cells and skeletal muscle myoblasts were transfected with the eukaryotic vectors of $\mathrm{N}$-terminal utrophin fragments bearing the FLAG-Tag at their C-terminus for immunodetection:

EUT11 (aa 1-543, CH1-CH2 actin-binding domain plus first two spectrin repeats);
EUT12 (aa 1-261, CH1-CH2 actin-binding domain alone);

EUT21 (aa 262-543, the first two spectrin repeats alone).

After spreading on the substratum, the COS7 cells display a fibroblast-like appearance as revealed by staining of the actin cytoskeleton with rhodamine-phalloidin (Figure 8). Differentiation and myotube formation were induced in the myoblasts by adding $1.8 \mathrm{mM} \mathrm{CaCl}_{2}$ and horse serum (Figure 9). As soon as the spindle-shaped diffusely staining myoblasts fuse to myotubes, an intensely stained cytoskeleton develops with cytoplasmic actin filaments filling the entire tubes. Only in one nontransfected myotube an early expression of sarcomeric striation can be seen (Figure 9(b)). In both types of cells, the transfected EUT12 neatly tracks the actin cytoskeleton and accumulates at the edges where the myotubes attach to the substratum. In the myotubes, the actin fibres could serve as scaffold for the nascent myofibrils as we have described earlier for the remodeling of rat cardiomyocytes in long-term culture [44]. Recombinant UTR261-GST (glutathione S-transferase) fusion-protein microinjected into chick embryo fibroblasts was shown to label stress fibres and focal contacts [34]. The diffuse staining for EUT11 comes as a surprise. Its repartition extends throughout the cells. In the myotube, it leaves the nuclei unstained and probably lines the membranes. Intact Up395 recognised by anti-UT31 against the rod domain (spectrin repeats R14R16) presents a discrete, diffuse staining throughout the COS7 cells (Figures 8(d) and 8(f)). This indicates that Up395 probably also lines the cell membrane attached to the cortical actin cytoskeleton, but it does not mark any stress fibrelike structures. Yet another feature holds for EUT21 which distinctly marks the nuclei, probably invading them.

Taken together, the staining pattern of EUT12 for actin filaments and of EUT11 for membranes may be interpreted as follows. The actin-binding domain alone (UT12 and EUT12) binds to actin filaments with high affinity in a $\mathrm{Ca}^{2+}$-independent manner. The actin binding plus first two spectrin domains (UT11 and EUT11) associate with membranes preventing the $\mathrm{N}$-terminus to bind to actin stress fibre-like structures, though the $\mathrm{N}$-terminus may still bind strongly to the cortical actin network lining the membranes. In other words, the two spectrin repeats associated with membranes, prevent the N-terminus from going astray by following the actin filaments throughout the cell body. UT11 and EUT11 correspond to the N-utro isoform, whose genomic derivation and protein we have described here. Thus, N-utro (1-539) may function as an ultrashort linker between cortical actin and the membranes. These properties may gain functional significance when $\mathrm{N}$-utro was present in sufficiently high concentration. In molecular terms, Nutro is $\sim 6$ times smaller than full-length Up395 and could represent a significant molecular fraction. Moreover, its repartition in different tissues could be concentrated at specific subcellular structures such as neural synapses or in epithelial and endothelial cell systems involved in barrier, secretory, and resorptive function as in kidney nephrons, 
vasculature, or blood-brain barrier. In all these cases, scaffold and signaling platforms require highly specialised subcellular localisation for interaction with myriads of proteins and other components [11, 12, 16, 17, 45].

\section{Conclusions}

We describe here a novel type of utrophin isoform that derives from its $\mathrm{N}$-terminus ( $\mathrm{N}$-utro). The various $\mathrm{C}$ terminal isoforms of utrophin and dystrophin correspond to each other except for Dp260 which has no analogue in utrophin. N-Utro also presents an exception as no analogous $\mathrm{N}$-terminal isoform from dystrophin is known so far. $\mathrm{N}$ utro has no relation to the utrophin/dystrophin-associated protein complex. Consequently, the function of $\mathrm{N}$-utro seems to differ from that of the full-length or C-terminal isoforms. Our immunocytochemical results indicate that Nutro could be responsible for the anchoring of the cortical actin cytoskeleton to the membranes. Possible association of $\mathrm{N}$-utro with additional proteins other than actin needs further exploration.

\section{Acknowledgments}

The authors thank Dr. M. Vasak and M. Knipp (Department of Biochemistry, University of Zurich, Switzerland) for help with the CD analysis, Dr. G. Frank (Institute of Molecular Biology and Biophysics, ETH Zurich, Switzerland) for microsequencing the purified recombinant proteins, Dr. S. J. Winder (Department of Biomedical Science, University of Sheffield, UK) for providing the human dystrophin minigene, and T. Grampp for skilled technical assistance. They are grateful for financial support by the Roche Research Foundation, Basel, Switzerland; Swiss Foundation for Research on Muscle Diseases, Basel, Switzerland; Hartmann Mueller Foundation, Zurich, Switzerland.

\section{References}

[1] J. M. Ervasti, "Costameres: the Achilles' heel of Herculean muscle," Journal of Biological Chemistry, vol. 278, no. 16, pp. 13591-13594, 2003.

[2] I. N. Rybakova, J. L. Humston, K. J. Sonnemann, and J. M. Ervasti, "Dystrophin and utrophin bind actin through distinct modes of contact," Journal of Biological Chemistry, vol. 281, no. 15, pp. 9996-10001, 2006.

[3] D. G. Allen and N. P. Whitehead, "Duchenne muscular dystrophy-what causes the increased membrane permeability in skeletal muscle?" International Journal of Biochemistry and Cell Biology, vol. 43, no. 3, pp. 290-294, 2010.

[4] J. M. Ervasti, "Dystrophin, its interactions with other proteins, and implications for muscular dystrophy," Biochimica et Biophysica Acta, vol. 1772, no. 2, pp. 108-117, 2007.

[5] M. Guglieri and K. Bushby, "Molecular treatments in Duchenne muscular dystrophy," Current Opinion in Pharmacology, vol. 10, no. 3, pp. 331-337, 2010.

[6] E. Le Rumeur, S. J. Winder, and J. -F. Hubert, "Dystrophin: more than just the sum of its parts," Biochimica et Biophysica Acta, vol. 1804, no. 9, pp. 1713-1722, 2010.

[7] J. Tinsley, N. Deconinck, R. Fisher et al., "Expression of fulllength utrophin prevents muscular dystrophy in mdx mice," Nature Medicine, vol. 4, no. 12, pp. 1441-1444, 1998.
[8] I. N. Rybakova, J. R. Patel, K. E. Davies, P. D. Yurchenco, and J. M. Ervasti, "Utrophin binds laterally along actin filaments and can couple costameric actin with sarcolemma when overexpressed in dystrophin-deficient muscle," Molecular Biology of the Cell, vol. 13, no. 5, pp. 1512-1521, 2002.

[9] A. Clerk, G. E. Morris, V. Dubowitz, K. E. Davies, and C. A. Sewry, "Dystrophin-related protein, utrophin, in normal and dystrophic human fetal skeletal muscle," Histochemical Journal, vol. 25, no. 8, pp. 554-561, 1993.

[10] A. J. Sutherland-Smith, C. A. Moores, F. L. M. Norwood et al., "An atomic model for actin binding by the $\mathrm{CH}$ domains and spectrin-repeat modules of utrophin and dystrophin," Journal of Molecular Biology, vol. 329, no. 1, pp. 15-33, 2003.

[11] C. Perronnet and C. Vaillend, "Dystrophins, utrophins, and associated scaffolding complexes: role in mammalian brain and implications for therapeutic strategies," Journal of Biomedicine and Biotechnology, vol. 2010, Article ID 849426, 19 pages, 2010.

[12] T. Haenggi and J. M. Fritschy, "Role of dystrophin and utrophin for assembly and function of the dystrophin glycoprotein complex in non-muscle tissue," Cellular and Molecular Life Sciences, vol. 63, no. 14, pp. 1614-1631, 2006.

[13] J. Donders and C. Taneja, "Neurobehavioral characteristics of children with duchenne muscular dystrophy," Child Neuropsychology, vol. 15, no. 3, pp. 295-304, 2009.

[14] T. S. Khurana and K. E. Davies, "Pharmacological strategies for muscular dystrophy," Nature Reviews Drug Discovery, vol. 2, no. 5, pp. 379-390, 2003.

[15] S. J. Winder, "The membrane-cytoskeleton interface: the role of dystrophin and utrophin," Journal of Muscle Research and Cell Motility, vol. 18, no. 6, pp. 617-629, 1997.

[16] T. Haenggi, A. Soontornmalai, M. C. Schaub, and J. M. Fritschy, "The role of utrophin and Dp71 for assembly of different dystrophin-associated protein complexes (DPCs) in the choroid plexus and microvasculature of the brain," Neuroscience, vol. 129, no. 2, pp. 403-413, 2004.

[17] T. Haenggi, M. C. Schaub, and J. M. Fritschy, "Molecular heterogeneity of the dystrophin-associated protein complex in the mouse kidney nephron: differential alterations in the absence of utrophin and dystrophin," Cell and Tissue Research, vol. 319, no. 2, pp. 299-313, 2005.

[18] T. M. Nguyen, T. T. Le, D. J. Blake, K. E. Davies, and G. E. Morris, "Utrophin, the autosomal homologue of dystrophin, is widely-expressed and membrane-associated in cultured cell lines," FEBS Letters, vol. 313, no. 1, pp. 19-22, 1992.

[19] D. J. Blake, J. N. Schofield, R. A. Zuellig et al., "G-utrophin, the autosomal homologue of dystrophin Dp116, is expressed in sensory ganglia and brain," Proceedings of the National Academy of Sciences of the United States of America, vol. 92, no. 9, pp. 3697-3701, 1995.

[20] A. P. Weir, E. A. Burton, G. Harrod, and K. E. Davies, "A- and B-utrophin have different expression patterns and are differentially up-regulated in mdx muscle," Journal of Biological Chemistry, vol. 277, no. 47, pp. 45285-45290, 2002.

[21] J. Wilson, W. Putt, C. Jimenez, and Y. H. Edwards, "Up71 and Up140, two novel transcripts of utrophin that are homologues of short forms of dystrophin," Human Molecular Genetics, vol. 8, no. 7, pp. 1271-1278, 1999.

[22] R. A. Zuellig, B. C. Bornhauser, I. Knuesel, F. Heller, J. M. Fritschy, and M. C. Schaub, "Identification and characterisation of transcript and protein of a new short N-terminal utrophin isoform," Journal of Cellular Biochemistry, vol. 77, no. 3, pp. 418-431, 2000.

[23] T. M. Nguyen, T. R. Helliwell, C. Simmons et al., "Full-length and short forms of utrophin, the dystrophin-related protein," FEBS Letters, vol. 358, no. 3, pp. 262-266, 1995. 
[24] M. M. Bradford, "A rapid and sensitive method for the quantitation of microgram quantities of protein utilizing the principle of protein dye binding," Analytical Biochemistry, vol. 72, no. 1-2, pp. 248-254, 1976.

[25] J. H. Han, C. Stratowa, and W. J. Rutter, "Isolation of fulllength putative rat lysophospholipase cDNA using improved methods for mRNA isolation and cDNA cloning," Biochemistry, vol. 26, no. 6, pp. 1617-1625, 1987.

[26] J. Sambrook, E. F. Fritsch, and T. Maniatis, Molecular Cloning: A Laboratory Manual, Cold Spring Harbor Laboratory, Cold Spring Harbor, NY, USA, 1989.

[27] U. K. Laemmli, "Cleavage of structural proteins during the assembly of the head of bacteriophage T4," Nature, vol. 227, no. 5259, pp. 680-685, 1970.

[28] J. D. Pardee and J. A. Spudich, "Purification of muscle actin," Methods in Cell Biology, vol. 24, pp. 271-289, 1982.

[29] J. T. Yang, C. S. C. Wu, and H. M. Martinez, "Calculation of protein conformation from circular dichroism," Methods in Enzymology, vol. 130, no. C, pp. 208-269, 1986.

[30] D. K. Nam, S. Lee, G. Zhou et al., "Oligo(dT) primer generates a high frequency of truncated cDNAs through internal poly(A) priming during reverse transcription," Proceedings of the National Academy of Sciences of the United States of America, vol. 99, no. 9, pp. 6152-6156, 2002.

[31] U. T. Shankavaram, W. C. Reinhold, S. Nishizuka et al., "Transcript and protein expression profiles of the NCI-60 cancer cell panel: an integromic microarray study," Molecular Cancer Therapeutics, vol. 6, no. 3, pp. 820-832, 2007.

[32] K. Ohlendieck and K. P. Campbell, "Dystrophin constitutes $5 \%$ of membrane cytoskeleton in skeletal muscle," FEBS Letters, vol. 283, no. 2, pp. 230-234, 1991.

[33] C. A. Moores and J. Kendrick-Jones, "Biochemical characterisation of the actin-binding properties of utrophin," Cell Motility and the Cytoskeleton, vol. 46, no. 2, pp. 116-128, 2000.

[34] S. J. Winder, L. Hemmings, S. K. Maciver et al., "Utrophin actin binding domain: analysis of actin binding and cellular targeting," Journal of Cell Science, vol. 108, no. 1, pp. 63-71, 1995.

[35] B. A. Renley, I. N. Rybakova, K. J. Amann, and J. M. Ervasti, "Dystrophin binding to nonmuscle actin," Cell Motility and the Cytoskeleton, vol. 41, no. 3, pp. 264-270, 1998.

[36] M. Way, B. Pope, R. A. Cross, J. Kendrick-Jones, and A. G. Weeds, "Expression of the N-terminal domain of dystrophin in E. coli and demonstration of binding to F-actin," FEBS Letters, vol. 301, no. 3, pp. 243-245, 1992.

[37] S. J. Winder and J. Kendrick-Jones, "Calcium/calmodulindependent regulation of the $\mathrm{NH} 2$-terminal F-actin binding domain of utrophin," FEBS Letters, vol. 357, no. 2, pp. 125128, 1995.

[38] Y. Gluzman, "SV40-transformed simian cells support the replication of early SV40 mutants," Cell, vol. 23, no. 1, pp. 175$182,1981$.

[39] E. Fabbrizio, A. Bonet-Kerrache, J. J. Leger, and D. Mornet, "Actin-dystrophin interface," Biochemistry, vol. 32, no. 39, pp. 10457-10463, 1993.

[40] B. J. Perrin and J. M. Ervasti, "The actin gene family: function follows isoform," Cytoskeleton, vol. 67, no. 10, pp. 630-634, 2010.

[41] I. N. Rybakova and J. M. Ervasti, "Dystrophin-glycoprotein complex is monomeric and stabilizes actin filaments in vitro through a lateral association," Journal of Biological Chemistry, vol. 272, no. 45, pp. 28771-28778, 1997.

[42] K. J. Amann, A. W. X. Guo, and J. M. Ervasti, "Utrophin lacks the rod domain actin binding activity of dystrophin," Journal of Biological Chemistry, vol. 274, no. 50, pp. 35375-35380, 1999.
[43] I. N. Rybakova and J. M. Ervasti, "Identification of spectrinlike repeats required for high affinity utrophin-actin interaction," Journal of Biological Chemistry, vol. 280, no. 24, pp. 23018-23023, 2005.

[44] M. E. Eppenberger, I. Hauser, T. Baechi et al., "Immunocytochemical analysis of the regeneration of myofibrils in longterm cultures of adult cardiomyocytes of the rat," Developmental Biology, vol. 130, no. 1, pp. 1-15, 1988.

[45] I. Knuesel, B. C. Bornhauser, R. A. Zuellig, F. Heller, M. C. Schaub, and J. M. Fritschy, "Differential expression of utrophin and dystrophin in CNS neurons: an in situ hybridization and immunohistochemical study," Journal of Comparative Neurology, vol. 422, no. 4, pp. 594-611, 2000. 

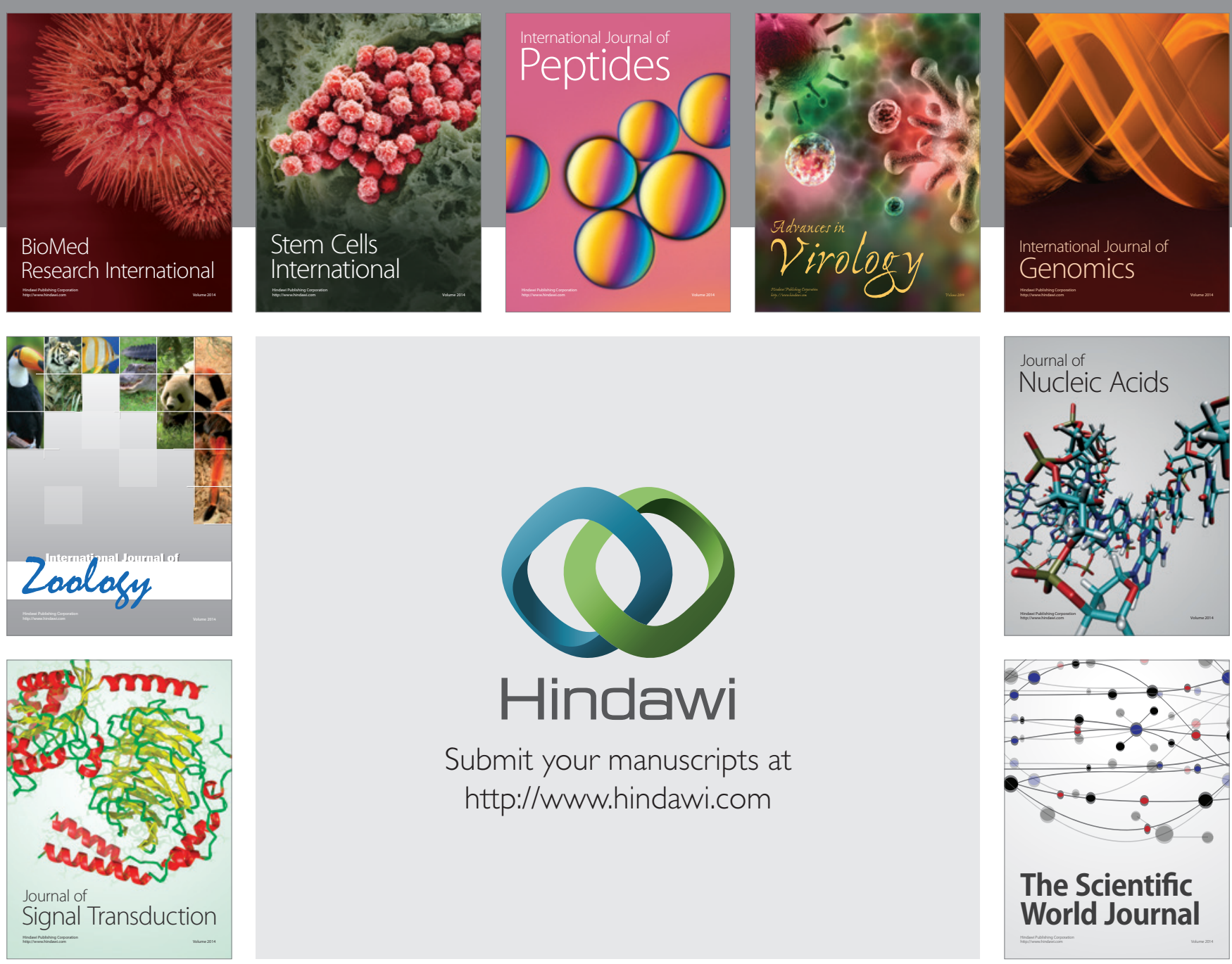

Submit your manuscripts at

http://www.hindawi.com
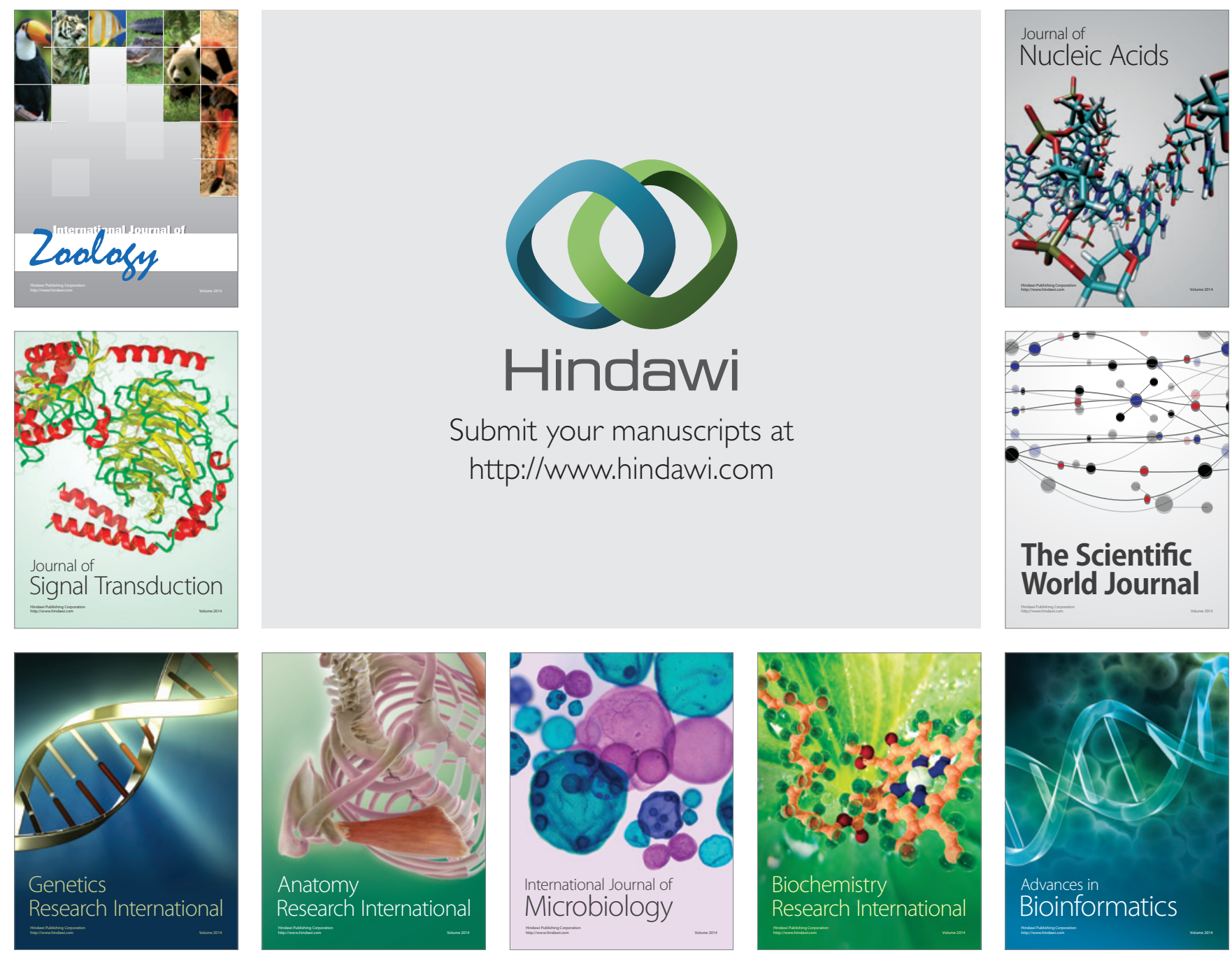

The Scientific World Journal
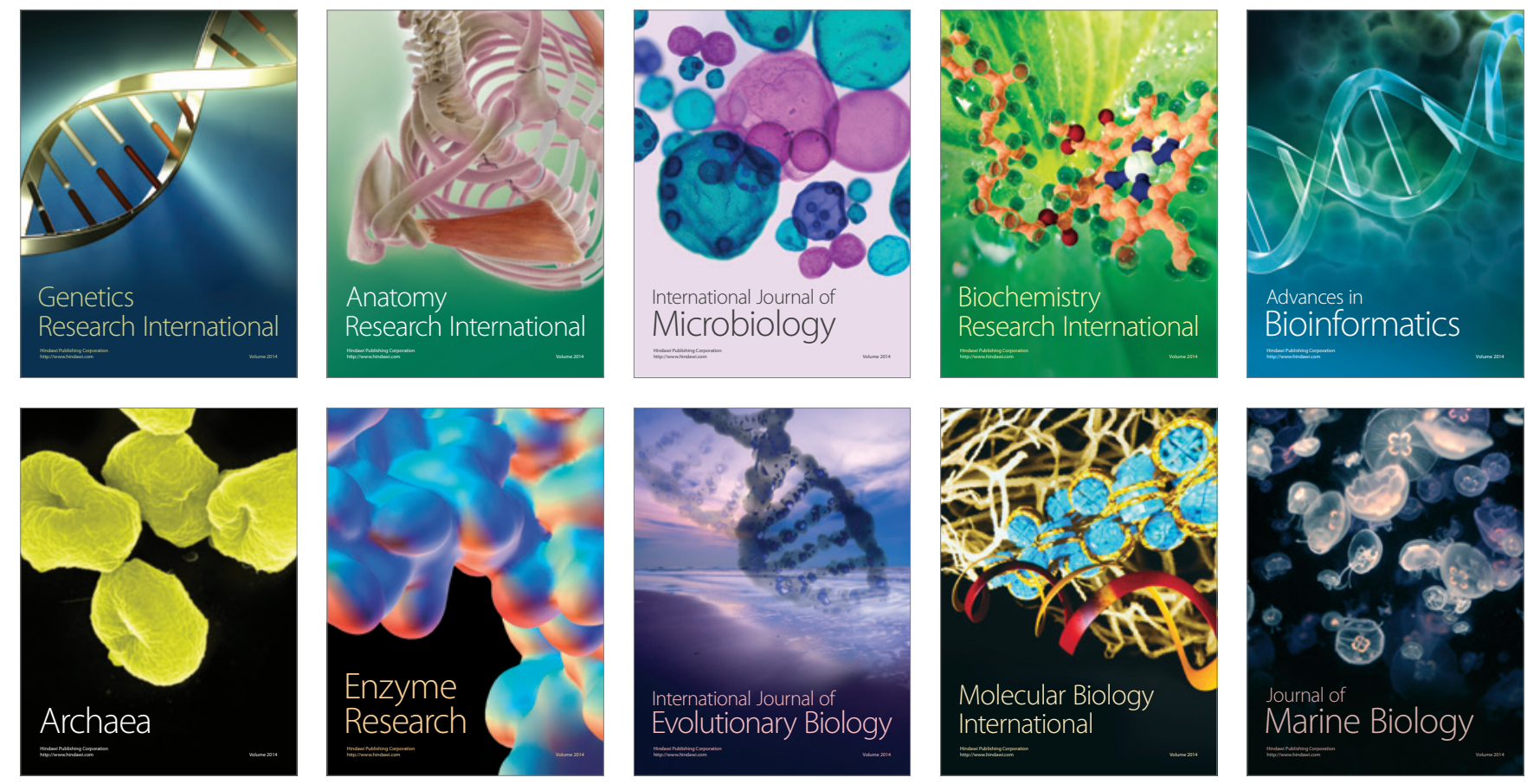